Non-peer reviewed EarthArXiv preprint.

Under review by Environmental Science, Policy, \& Management.

\title{
Holistic systems-thinking for policy coherence: A case study of socio-institutional challenges and opportunities for improved adoption of nature-based solutions
}

Cyndi V. Castro ${ }^{*}$

${ }^{a}$ Civil and Environmental Engineering, University of Houston, Houston, Texas 77204, USA

* Corresponding author. E-mail address: cvcastro@uh.edu (C.V. Castro).

\section{Highlights}

- NBSs have not reached full potential due to dynamic socio-institutional factors.

- Feedback loops within the system may result in policy synergy or conflict.

- Causal maps help define such feedbacks but are difficult to analyze at large-scale.

- Systems-thinking is used to illustrate a causal archetype for human-NBS feedbacks.

- Policy scenarios are simulated with fuzzy maps and compared to causal loop behavior.

\section{Graphical abstract}

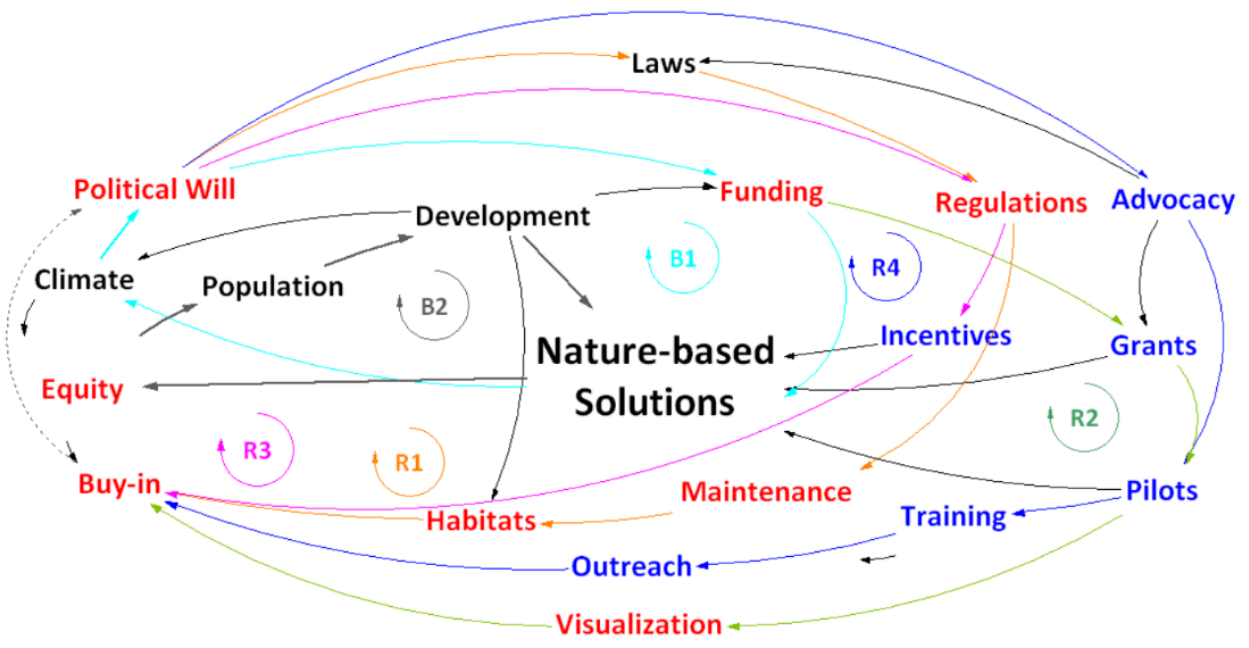

\section{Keywords}

Causal loop diagram, fuzzy cognitive mapping, feedback loops, human-water systems, scenario building, sustainable decision-making 
Non-peer reviewed EarthArXiv preprint.

Under review by Environmental Science, Policy, \& Management.

\section{Abstract}

Nature-based solutions (NBSs) are often managed according to hydro-environmental characteristics that disregard the complex interactions between decision-makers, society, and the environment. Numerous barriers to NBS adoption have been identified as stemming from human behavior (e.g., community buy-in, political will, culture), yet we lack an understanding of how such factors interrelate to inform policy design. The identification of synergies and trade-offs among diverse management strategies is necessary to generate optimal results from limited institutional resources. System dynamics modeling (SDM) has been used within the environmental community to aid decision-making by bringing together diverse stakeholders and defining their shared understanding of complex behavior. While these approaches have enhanced collaboration efforts and have increased awareness of complexity, SDM models often result in numerous feedback loops that are difficult to disentangle without further, data-intensive modeling. When investigating the complexities of human decision-making, we often lack robust empirical datasets for SDM quantification. An alternative to SDM is fuzzy cognitive mapping (FCM), which combines the strengths of stakeholder knowledge with network theory to produce semi-quantitative scenarios of system change. However, sole reliance upon computer-simulated outputs may obscure our understanding of the underlying system behavior. Therefore, the aim of this study is to assess the applicability and strength of combining SDM and FCM to both identify areas of policy coherence from stakeholder engagement and also to explain the emergence of synergies and trade-offs according to causal loop logic. This framework is demonstrated through a case study of NBS policy-making and socio-institutional feedbacks in Houston, Texas, USA.

\section{Introduction}

As climate change and urban densification continue to rise, traditional stormwater systems are being challenged by limited conveyance capacitance and expensive mitigation strategies (ASCE, 2020). Many communities are considering soft-scale nature-based solutions to complement existing drainage networks by emulating natural watershed processes and limiting the amount of stormwater runoff entering the system (Demuzere et al., 2014). Common NBSs include rain gardens, green roofs, retention ponds, bioswales, water cisterns, and permeable pavements, which operate collectively to mitigate stormwater volume while delivering numerous co-benefits (Ruangpan et al., 2020). The United Nations Environmental Programme (UNEP) has positioned that the restorative properties of NBSs may significantly bend the curve of climate change and biodiversity loss (UNEP, 2019) and deemed NBSs as an essential component of climate adaptation and mitigation (UN Environment Programme, 2019). A workshop conducted by the UNEP's Intergovernmental Panel on Climate Change (IPCC) revealed that complex policy-making and social dynamics are key impediments to NBS uptake and recommended a major shift toward co-produced knowledge between practitioners and researchers to overcome such implementation challenges (Frantzeskaki et al., 2019).

While there have been numerous attempts to incorporate social co-benefits into NBS planning (Raymond et al., 2017), there exists a lesser understanding of how societies, in turn, impact NBS potential (Nesshöver et al., 2017). Observational case studies have identified several key challenges to NBS uptake, including public perception (Baptiste et al., 2015), local culture (Derkzen et al., 2017), institutional frameworks (Solheim et al., 2021), and technical roles (Zuniga-Teran et al., 2020) (literature review summarized in Table A1). While these barriers have been studied as isolated events, we lack an understanding of how such factors operate holistically and influence one another. When human actors interact with NBS systems through planning and group behavior, social and political constructs adapt to the new environment, which further refines local values and drives emergent phenomena. Each cycle of this complex system denotes an additional human-NBS response, which must be assessed according to altered 
Non-peer reviewed EarthArXiv preprint.

Under review by Environmental Science, Policy, \& Management.

characteristics. Therefore, we cannot mitigate the system by simply assigning policies that resolve select barriers (e.g., Table A1) and assume the results will be proportionally related to the change. Instead, we must be able to incorporate human agency as an endogenous component that influences and co-evolves with the physical systems they seek to shape. For this, we require the coupling of human behavior with NBS responses, which may be accomplished through a holistic application of systems-thinking.

\subsection{A holistic systems-thinking paradigm}

The systems-thinking process involves a series of phases, often performed in sync with modelers and stakeholders, to understand how complex phenomena operate. These phases (i.e., dynamic-thinking, causal-thinking, feedback-thinking, and strategy-thinking) are depicted in Fig. 1 and described in terms of the common phenomena they seek to address. The premise of systems-thinking is that complex issues can be better understood when the individual components of the system are identified and the causal links between them are associated (Allen, 1988). The initial stages of systems-thinking often include 1) Group Model Building (GMB), which is used to derive a community understanding of the dynamic problem and associated variables through stakeholder interactions (e.g., workshops, interviews), and 2) Causal Loop Diagrams (CLD), which are simplified graphical representations of the stakeholder-defined variables and their interactions that form feedbacks (Forrester, 1994). These feedbacks may connect to form closed loops, which define the system trajectory as either balancing (i.e., trending toward equilibrium) or reinforcing (i.e., propagating change) (Sternam, 2002). Large CLDs are often too convoluted for practical inference of policy implications from a visual analysis of the many interactive feedbacks within the system (Bureš, 2017; Osoba and Kosko, 2019). System dynamics modeling (SDM) is then the translation of these feedbacks into a quantified model to simulate the associated dynamics, which may be used to test unique hypotheses for robust decision-making (Richmond, 1993). A common SDM technique is a stock-and-flow diagram (SFD), which simulates accumulations and changes within the system through a set of integral equations. SFD models require numerical descriptions of system performance over time, which are not often available when considering novel policies and the dynamics of human behavior (Bureš et al., 2020).

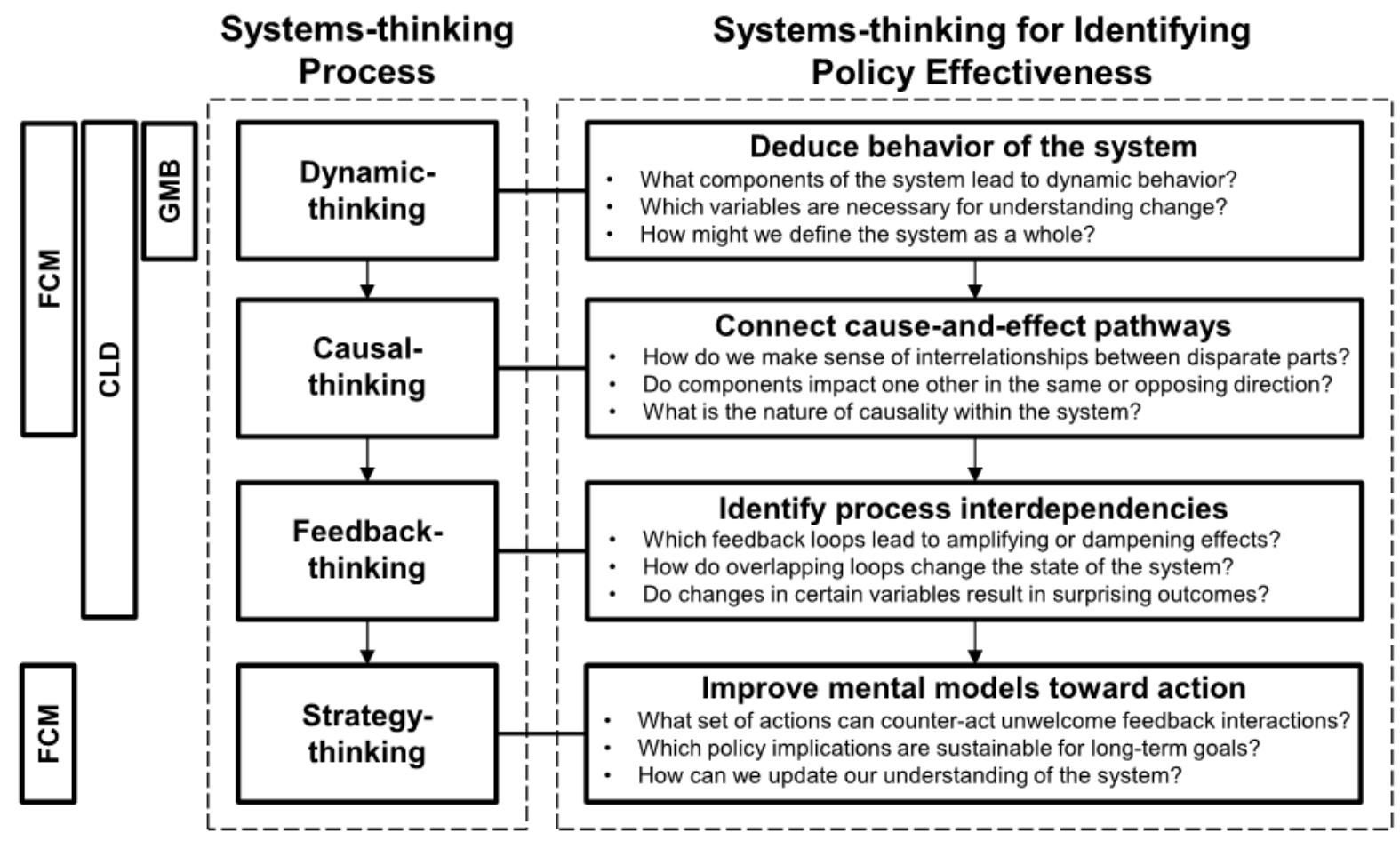

Fig. 1. General framework of how a holistic application of systems-thinking can be used to define complex, dynamic systems and assess policy effectiveness for a set of management strategies. The boxes on the left represent the common systems-thinking processes included within each of the primary modeling approaches (CLD = causal loop 
Non-peer reviewed EarthArXiv preprint.

Under review by Environmental Science, Policy, \& Management.

diagramming, FCM = fuzzy-cognitive mapping, GMB = group model building). [Graphic loosely adapted from (Kim et al., 2017), text updated.]

An alternative to SDM modeling is fuzzy cognitive mapping (FCM), which was first proposed by (Axelrod, 1976) using constructivist psychology and optimized by Kosko (1986) from advances in mapping theory (Raskin, 2002). FCMs are semi-quantitative maps that use communal knowledge and perception to define dynamic system components and parameterize the strengths of their causal relationships. The values in FCM maps are fuzzy (i.e., linguistic/qualitative) representations of human beliefs about how the system components respond to each other. FCMs allow for the rapid assessment of system alternatives through "what-if" scenarios according to network/graph theory (Voinov et al., 2018). FCM-based scenarios facilitate a dynamic understanding of complex human-environmental phenomena that may have otherwise been difficult, or impossible, to assess through traditional empirical approaches (Gray et al., 2014; Özesmi and Özesmi, 2004).

Several state-of-the-art reviews have highlighted a rise in systems-thinking approaches within environmental sciences (Mashaly and Fernald, 2020; Moon, 2017; Turner et al., 2016; Zomorodian et al., 2018). SDM concepts have been used to support decision-making for complex water management systems, such as urban water supply (House-Peters and Chang, 2011), flood protection (Perrone et al., 2020), irrigation (Pluchinotta et al., 2018), and agriculture (Inam et al., 2015). Other studies have applied SDM to better understand hydrological relationships and to simulate complex watershed responses (e.g., Keshta et al., 2009; Li and Simonovic, 2002). Moreover, the field of socio-hydrology has proliferated by applying system dynamics to better understand how society has co-evolved with water over time (Pande and Sivapalan, 2017). Research has begun to emerge where systems-thinking has been applied to NBSs to facilitate an understanding of overlapping co-benefits and to promote stakeholder involvement (Coletta et al., 2021; Giordano et al., 2020; Gómez Martín et al., 2020; Pagano et al., 2019; Santoro et al., 2019).

Many of these studies have rightly applied dynamic- and causal-thinking to define the nature of complex human-environmental systems (Mashaly and Fernald, 2020). Some studies have also explored alternative management strategies through FCM-based scenarios (e.g., (Giordano et al., 2020; Gómez Martín et al., 2020; Kokkinos et al., 2020)) and SFD models (e.g., (Kotir et al., 2016; Pagano et al., 2019; Sušnik et al., 2012)). Additional research has applied feedback-thinking to characterize system behavior into archetypes, which are typically described with storylines and narratives (e.g., (Bahri, 2020; Gebrai et al., 2021)).

These studies operate under the assumption that dominant feedback loops within the system may be used to inform management of key leverage points and to facilitate which types of action would result in optimal results. However, quantitative investigations of how system feedbacks interact to inform strategy are typically reserved for the SFD phase, which involve significant investment in resources, data, and time. Manual interpretations of feedback structures are often not feasible given the large magnitude of many dynamic systems. For example, Brennan et al., (2015) applied a systems-thinking approach to better understand how various policies could impact social health across a large community. This study resulted in 50 unique CLDs (590 participants, 227 variables, 1555 feedback loops). To derive insights from the data, the 50 CLDs were synthesized into one composite diagram using the variables that were consistently identified $20 \%$ of the time. In such an approach, it could be argued that much of the causal richness is lost when $\sim 80 \%$ of the variables proposed by the community are discarded. Aggregation of causal relationships to aid human understanding is a common necessity within system dynamics (Ryan et al., 2021), especially considering the limitation of reliable datasets for model quantification (e.g., SFDs) (Mirchi et al., 2012).

\subsection{Policy coherence: synergies and trade-offs}

As described by Richardson (2011), the foundations of systems-thinking extend far beyond stakeholder participation and derivation of causal structures. Systems-thinking, when applied holistically, can be used to reveal how human actions may impact the state of a dynamic system according to local knowledge embedded within real-world experiences. Dynamic-, causal-, and feedback-thinking elicits crucial information about the direction and central relationships of the system, which could reveal compensatory effects of human-environment behavior (Richardson, 2011). However, without an understanding of the strengths of the system feedbacks (e.g., through FCM-based modeling), identifying such compensations may become elusive. An example is presented in Fig. 2 to demonstrate this idea: 
Non-peer reviewed EarthArXiv preprint.

Under review by Environmental Science, Policy, \& Management.

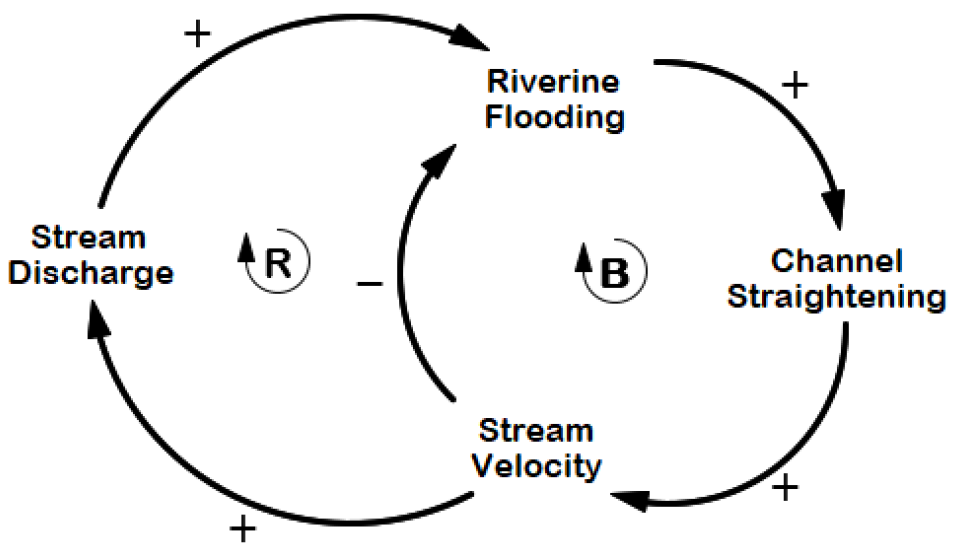

Fig. 2. Hypothetical causal loop graphic depicting potential policy conflict (or synergy) resulting from interaction of two opposing feedback loops. Balancing loop is denoted with " $\mathrm{B}$ " to describe the tendency of channel straightening to reduce riverine flooding by increasing stream velocity. Synchronous reinforcing loop is denoted with " $R$ " to highlight the amplifying effects of the channel intervention on stream discharge and, potentially, riverine flooding elsewhere within the system.

A common approach in flood management involves converting natural streams into concrete-lined channels to reduce riverine overflow by rapidly transitioning water further downstream. Such feedbacks may be described by the balancing loop in Fig. 2, where the riverine dynamics are altered to increase stream velocity and mitigate flooding. However, increased stream velocities at the project location may result in flooding elsewhere if the downstream discharge is not carefully balanced to accommodate additional inflow. Ideally, the reinforcing loop in Fig. 2 would remain weaker than the balancing loop through careful engineering. However, this figure showcases how a policy change in one portion of the system could result in adverse impacts elsewhere (e.g., amplified flooding downstream), thereby highlighting the need to understand the causal structure of the system and the strengths of the interacting loops.

Policy coherence is used to describe the extent to which a given policy (or set of policies) imposed on a system result in optimal interactions between the system sub-components toward achieving the overall goal. While the literature is not consistent in defining policy coherence, this term is typically understood to define the areas of synergy and conflict between sets of policy choices within the system (Muscat et al., 2021; Reyes-Mendy et al., 2014). Policy conflict is used within the environmental literature to describes the same phenomenon in the SDM literature called "policy resistance", where well-intentioned management strategies may be hindered by unforeseen consequences that evolve from systematic feedbacks (Sternam, 2002). Kotir (2020) describes policy resistance as "the tendency for an intervention to be jeopardized by the system's response to the intervention itself". Within the system dynamics literature, the primary means for circumventing policy resistance is to transition the planning paradigm from a reductionist worldview toward a greater awareness of and appreciation for complexity. By approaching the problem as a dynamic structure of moving parts, each impacting one another through causality, an assessment of interacting feedbacks is assumed to reveal how the system would react if one of the components were altered by policy intervention (Roxas et al., 2019). However, as previously discussed, such assessments by visualization alone become impossible as the system grows larger.

According to John Sterman, a leader in SDM:

"Even if our cognitive maps of causal structure were perfect, learning, especially double-loop learning, would still be difficult. To use a mental model to design a new strategy or organization we must make inferences about the consequences of decision rules that have never been tried and for which we have no data. To do so requires intuitive solution of high-order nonlinear differential equations, a task far exceeding human cognitive capabilities in all but the simplest systems." (Sternam, 2002). 
Non-peer reviewed EarthArXiv preprint.

Under review by Environmental Science, Policy, \& Management.

Policy synergy is a term used to describe how well combined management strategies interact as a cohesive unit to accomplish more than the sum of the results for each separate policy. In other words, policies that exhibit synergy reinforce one another, according to the dynamic properties of the system feedbacks and their internal strengths, to manifest the policy objectives (Muscat et al., 2021; Nilsson et al., 2012). In adopting the view that policy coherence is the increase in synergies and reduction in conflicts, it becomes clear that we should both identify interacting feedback loops from an SDM-based perspective and also identify which loops tend to drive the system response according to feedback strengths (i.e., FCMbased modeling). Failure to understand these processes often results in reductionist interventions aimed at "fixing" one facet of the problem, which may initiate non-optimal system behavior and defeat the original policy goal (Agyepong et al., 2012). To address such complex questions, this study stresses that the full scope of systems-thinking provides the optimal means for elucidating policy coherence by seizing and integrating the strengths from both SDM and FCM-based paradigms.

\subsection{The need for integrated approaches}

There have been several examples within the environmental literature of combining traditional SDM concepts with FCM-based scenarios for assessment of complex systems (e.g., (Coletta et al., 2021; Hafezi et al., 2020; Ruiz and Sanz-Sánchez, 2020)). However, such studies have generally considered the effect of different environmental phenomena on system performance (e.g., land use change, climate change, cobenefits production), and have not been used to assess policy effectiveness. Studies that have applied systems-thinking to assess policy coherence have typically relied on manual interpretation of complex CLD feedback loops and a qualitative presentation of results (e.g., (Collins et al., 2013; Paterson and Holden, 2019; Stepp et al., 2009)). FCM-based scenarios for evaluating policies have typically highlighted the strengths of individual variables toward system goals with lesser discussion regarding how the feedback loops (balancing and reinforcing) interacted to produce such behavior (e.g., (Olazabal et al., 2018; Singh and Chudasama, 2020)). Instead, the complexities of the feedbacks are embedded within the numerical simulation and not used to inform how the balancing and reinforcing dynamics produce policy conflict or synergy (Harich, 2010). As such, FCM-based scenarios, when used in isolation, may be deemed black-box methods that obscure the non-linear developments emerging from within the system and how their interrelationships influence policy relations (Kaljonen et al., 2012).

There have been calls within the literature to more clearly identify policy effects from FCM-based simulations by exploring the causal loops underlying the system structure and their resulting behaviors (de Gooyert et al., 2016). To address this gap, this study integrated qualitative and semi-quantitative modeling, thereby revealing systemic interactions that would not be clear from CLD or FCM alone, but which also do not require complex numerical modeling (i.e., SFDs). The proposed framework promoting a deeper awareness of dynamic feedbacks in the initial planning of complex systems and denotes the elucidation of policy coherence as a primary goal for holistic systems-thinking. By amalgamating cognitive modeling with causal loop logic, we extend beyond identifying the nature of the system to also elucidate the behavior and structure of the system amidst complex policy-driven interactions.

\section{Methodology: Applied to a case study in Houston, TX}

To explore the feedback effects of system dynamics on NBS policies, a half-day virtual workshop was conducted with stakeholders from the greater-Houston metropolitan region. A group model-building (GMB) session was executed to elucidate prominent relationships between NBS adoption and various social and institutional constructs, as observed by local stakeholders. The environmental feedbacks between NBSs and humans were also highlighted through this exercise by encouraging the stakeholders to consider relationships between NBS outputs and complex variables such as climate change or social equity.

A semi-structured scripting protocol was used to guide the stakeholders in deriving a shared CLD and identifying the strengths of internal relationships. The causal system was then transposed into a weighted FCM, which was used to simulate various "what-if" management approaches. For each simulation, a unique policy (or set of policies) was propagated throughout the system to identify relative change of NBS implementation. The collective strategies were compared and ranked to elucidate areas of policy synergy and conflict. Finally, the balancing and reinforcing properties of the CLD feedback loops were used to confirm and better understand the policy implications resulting from the FCM-based scenarios. 
Non-peer reviewed EarthArXiv preprint.

Under review by Environmental Science, Policy, \& Management.

\subsection{Group model-building}

\subsubsection{Selecting pertinent stakeholders}

The virtual stakeholder workshop was held on July 9, 2021 to capture the mental models of experts who had recently been involved with NBS implementation efforts in Houston, Texas, USA. The workshop included nine participants across three jurisdictional scales (i.e., local, municipal, and regional-level). Each of the stakeholders were well-known within the community as having a historical involvement in NBS adoption and/or policy design. Several of the participants were previously involved in developing guidelines associated with NBS initiatives and frameworks. For example, local NBS adoption was encouraged through the "Incentives for Green Development" program, which supported green development through project awards, tax abatements, and expedited permits (Bloom et al., 2019). The "Resilient Houston" strategy also promoted sustainable infrastructure by identifying goals for green development and by highlighting the role of NBSs in climate mitigation, social equity, and water management (Aho and Sarkozy-Banoczy, 2020). A community-driven "Houston Climate Action Plan" recommended evidence-based strategies to achieve carbon neutrality, which included enhanced levels of green space throughout the city (City of Houston, 2020). Regional partners had also encouraged nature-based development through numerous design standards, planning guidelines, and pilot projects (HCFCD, 2020; RGME, 2021; Storey et al., 2011). Moreover, several taskforces had been deployed to integrate community members with city and county officials toward further NBS development. Appendix Table A2 summarizes the various institutions, roles, and NBS backgrounds represented within the GMB workshop.

\subsubsection{Facilitating the stakeholder workshop}

The workshop was facilitated by leading the participants through a series of GMB scripts, which are detailed in the supplementary material (Text S1). Scripting is a common practice in systems-thinking research for fostering a collective understanding of how complex systems operate. The use of scripts spawned from Andersen and Richardson's (1997)'s call to transition GMB, which was initially founded within the social sciences, toward inter-disciplinary research by documenting best-practices for community modeling. The scripts are typically intended for live workshops and encompass a range of topics, including workshop preparation (stakeholder selection, room logistics, scheduling), group interaction (complexthinking skills, hopes and fears), causal loop modeling (variables, causal relationships, dynamic structure), and follow-up (model review, reflection, feedback, action) (Hovmand et al., 2011).

The following scripts were used for the NBS case study:

1) Logistics and Room Set-up: Used to format the virtual environment by identifying necessary tools and exploring options within the workshop platform.

2) Chicken and Eggs Example: Used to introduce the concept of a dynamic systems and causal loop models by depicting a story of chickens who needed to cross a busy road due to over-population. Feedbacks included birth, death, and management interventions to aid the chicken population (e.g., installing traffic barriers, building a fence, removing chickens).

3) Variable Elicitation: Used to facilitate a group discussion and identify causal variables to describe social and institutional feedbacks associated with nature-based solutions (including both barriers to and responses from successful implementation of nature-based solutions).

4) Causal Mapping with Seed Structure: Used to quickly illustrate a system of interacting feedbacks using seed variables from Script 3. Demonstrates concepts of causation, polarity, balancing and reinforcing loops, and dynamic change.

5) Creating Causal Loop Diagram from Variable List: Used to translate the identified variables into causal relationships and to define the strength of each feedback.

6) Model Review: Used to elicit the balancing and reinforcing loops within the system and to guide reflection of the major feedbacks. Model-based insights emerge from the interaction of multiple feedback loops. 
Non-peer reviewed EarthArXiv preprint.

Under review by Environmental Science, Policy, \& Management.

The scripts were slightly customized to foster a virtual workshop environment, as depicted in the supplementary material (Text S1). The stakeholders were guided through each script in successive order. Hypothesized variables were identified on a virtual whiteboard through a collective group discussion. The facilitator then drew the causal relationships, as defined by the stakeholders, within a web-based platform for real-time visualization and optimization. After the workshop, the causal loop sketch was converted into a CLD using Vensim SDM software and then emailed to the stakeholders for validation. A verbal transcript of the recorded session was reviewed during the translation process to ensure the variables and causal relationships were correctly identified and to highlight any areas of ambiguity.

\subsubsection{Eliciting system variables}

Prior to the workshop, the author identified key socio-institutional variables impacting NBS implementation according to the literature (Table A1) and grouped the factors within four primary themes to differentiate the dynamic components of the system (e.g., community buy-in, social culture, institutional characteristics, and engineering and maintenance). These themes where then further categorized into socio-institutional barriers, management opportunities, and exogenous factors for the workshop. During the preparation phase (Script 1), a virtual whiteboard was drafted with themed boxes, each color-coded for coherency of variable-types throughout the GMB process. One seed variable was inserted within each box as a preliminary example.

During the workshop, the stakeholders were introduced to a CLD example (Script 2), which provided a foundation for the types of variables to be considered in systems modeling. The stakeholders were then shown the virtual whiteboard and asked to consider how unique factors have limited or advanced NBS efforts according to their local experiences. Through a group discussion, participants described numerous causal factors associated with NBS implementation (Script 3). The variables were documented by the facilitator in real-time and grouped according to theme. The live whiteboard session from the workshop is depicted in the supplementary material (Fig. S1).

\subsection{Structuring a causal loop model}

The facilitator then selected several variables from the elicitation exercise and drew them as nodes within a live web-based platform (Text S2). Causal relationships and feedback loops were described and demonstrated visually within the shared web interface (Script 4). The participants were then asked to describe their understanding of dynamic behavior between the different elements (Script 5), which stimulated robust considerations of the underlying dynamics. During the live modeling session, CLD connections were drawn as one-way arrows between variables using the following polarity notations: positive (+), such that related variables changed in the same direction, or negative (-), where a change in one variable had an opposing impact on the linked variable. The stakeholders were also asked to define, qualitatively, the strength of connections between each variable, which were recorded by the facilitator (see Fig. S2). For purposes of simplicity, the GMB exercise did not consider time delays, as the resulting CLD was not intended for predictive SDM modeling. This approach was meant to mimic the use of color-coded sticky notes often used in GMB (Andersen and Richardson, 1997; Inam et al., 2015), thereby facilitating a virtual workshop environment with interactive group discussions and real-time causal loop diagramming.

The facilitator then translated the causal loop sketch into a CLD using the Vensim software, which is a widely-used system dynamics platform (Eberlein and Peterson, 1992). During the translation process, causal connections were compared to the recorded workshop transcript and optimized, as necessary, for coherency. For example, floods and climate change were noted as redundant variables (as they both provided a similar exogenous impact in the system) and were therefore merged by the modeler. The optimized CLD was emailed to all stakeholders for final validation, and no discrepancies were noted.

\subsection{Defining a weighted fuzzy cognitive map}

The preceding steps identified the stakeholders' understanding of key system variables and how they interact amongst one another to facilitate, or hinder, local NBS implementation. These system components provided the qualitative foundation for explaining causal relationships. Next, the CLD was transposed into a semi-quantitative FCM model using the web-based mapping suite Mental Modeler (Gray et al., 2013), a necessary step to structure the system for dynamic scenario-building of decision-making strategies (Gray 
Non-peer reviewed EarthArXiv preprint.

Under review by Environmental Science, Policy, \& Management.

et al., 2015). To prepare the map for scenario development, the causal variables were identified as either: 1) Management opportunities $=$ variables that were able to be altered by this specific cohort of stakeholders, or 2) Exogenous factors = variables that impacted the system but which the stakeholders did not possess decision-making power to change, as depicted in Fig. 3.

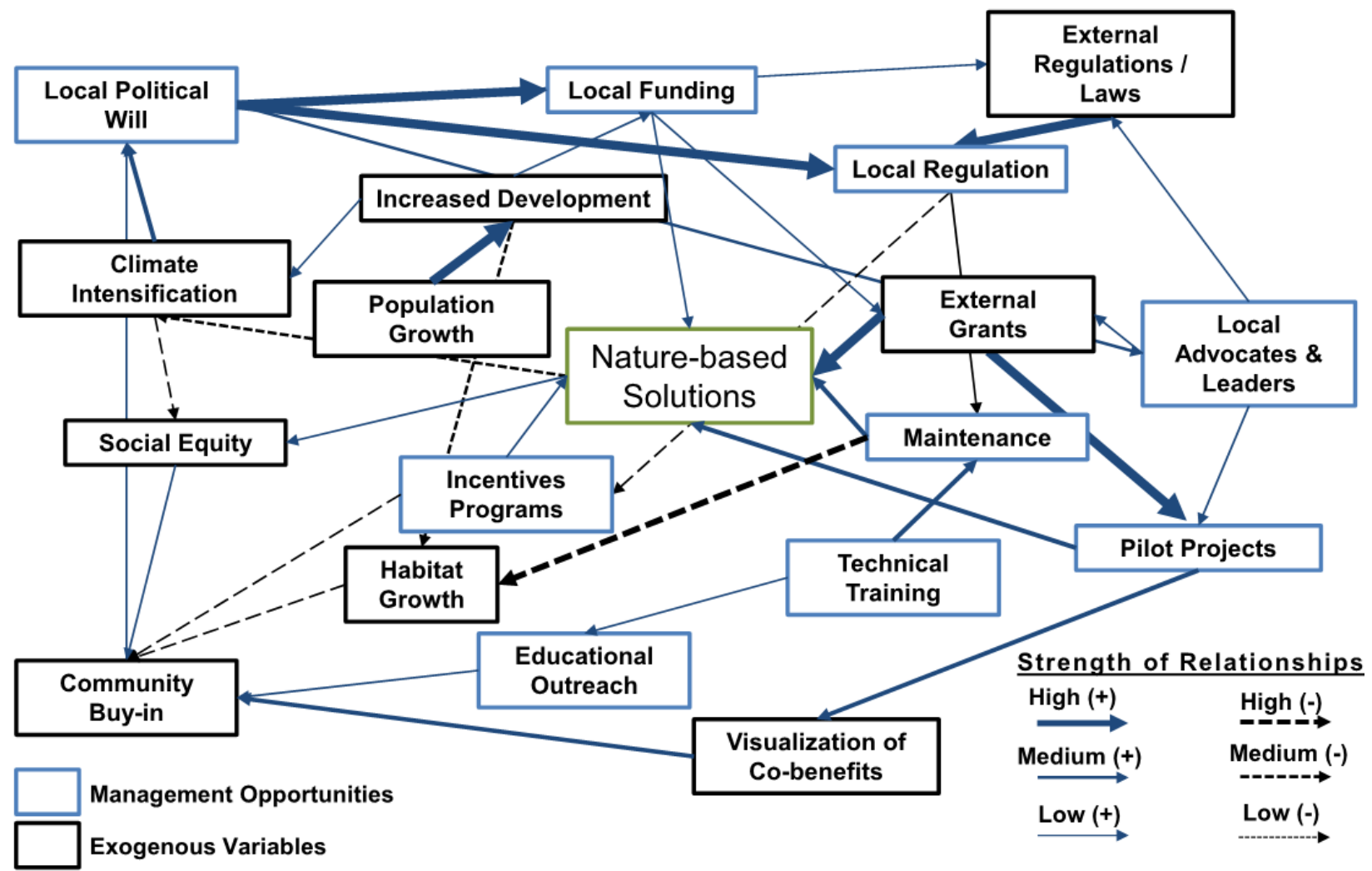

Fig. 3. Summary of key variables elicited by the stakeholder group describing socio-institutional challenges, exogenous factors, and management opportunities within the human-NBS system. Blue boxes = management opportunities, within the scope of stakeholder influence. Black boxes = exogenous variables, outside the scope of stakeholder influence. Green box = system goal variable. Blue arrows = ' + ' polarity. Black, dashed arrows = '-' polarity. Strengths of connecting arrows are represented by line weights, as defined in the legend. Note: Color should be maintained when printed.

The degree of influence for each causal link was then defined with fuzzy logic according to the stakeholder perceptions during the GMB session. A weight of -1 to +1 was used to identify the strengths of system feedbacks according to the following categories and respective scores: low strength $( \pm 0.25)$, medium strength $( \pm 0.50)$, high strength $( \pm 0.75)$, where ' + ' represented positive causality, and '-' described negative causality. A score of \pm 1.00 was reserved for "clamping" key decision variables for scenario development, further described in Sect. 2.4. Because FCMs are derived from graph theory, the system structure may also be represented mathematically by a square adjacency matrix ( $i \times j$ variables). The NBS cognitive map was translated into an adjacency matrix to summarize the connectivity strengths between each of the FCM variables (depicted in the supplementary material, Table S2).

\subsection{Simulating numerous management strategies}

The management opportunities were incorporated into "what-if" scenarios to better understand how a change in local policy would impact the resulting state of the NBS variable. FCM-based scenarios are used to alter specific variables and trace causal propagation throughout the system. FCM simulations use the adjacency matrix to represent the strengths of interconnections and state vectors to characterize the degree of variable change once a scenario is activated. Here, the degree of activation for each variable within the proposed management strategy was assigned a value of +1.00 , also known as "clamping" within the FCM literature (Gray et al., 2015), and the feedback effects on the NBS state vector were noted. FCM-based 
Non-peer reviewed EarthArXiv preprint.

Under review by Environmental Science, Policy, \& Management.

scenarios quantify dynamic interactions between system components for discrete time-steps until the system converges to equilibrium by applying formalized activation rules and transformation functions to the adjacency matrix. This study used the Kosko's activation rule (Eq. 1) and the hyperbolic transformation function (Eq. 2) in Mental Modeler, which are detailed by Gray et al. $(2015,2013)$.

$$
a_{i}^{(t+1)}=f\left(\sum_{j=1}^{n} w_{j i} a_{j}^{(t)}\right)
$$

where, $A_{i}^{(t+1)}$ represents the value of variable $V_{i}$ at time step $t+1, w_{j i}$ is the weight of connection between variable $V_{i}$ and $V_{j}, n$ describes the total number of variables in the system, $A_{j}^{(t)}$ represents the numerical value of variable $V_{j}$ at time step $t$, and $f$ is the transformation function.

$$
f(x)=\frac{e^{2 x}-1}{e^{2 x}+1}
$$

The final FCM contained 9 management opportunities out of the 19 total system variables. The system variables that were deemed to be within the stakeholders' influence included: Educational Outreach (EO), Technical Training (TT), Pilot Projects (PP), Incentives Programs (IP), Advocacy and Leadership (AL), Political Will (PW), Maintenance (MT), Funding (FU), Regulations (RE). From these variables, 129 fuzzy scenarios were identified by assuming the stakeholders would implement either a single policy $(n=9), a$ combined set of two policies $(n=36)$, or a combined set of three policies $(n=84)$, further described in Sect. 2.5. An example of the outputs from FCM-based scenario-building is demonstrated in Fig. 4, where unique variables are clamped to assess dynamic system change in the remaining state variables.

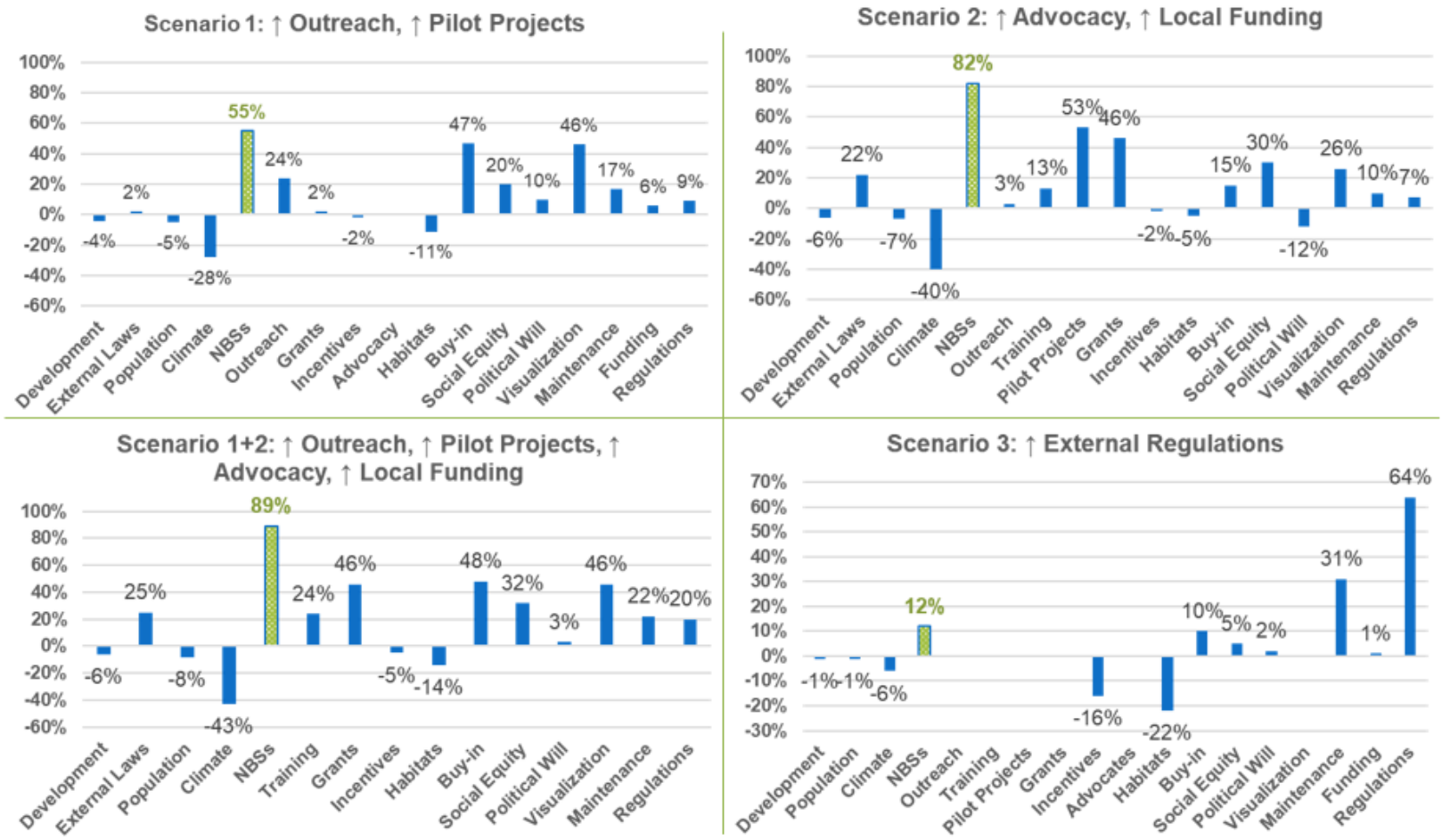

Fig. 4. Scenario output from fuzzy-cognitive mapping (FCM)-based model, whereby the policy variable(s) listed in each chart title are "clamped" to a value of +1.00 , and the system is activated according to Kosko's activation rule and the hyperbolic transformation function. The system stabilizes after a number of time-steps, and the changes in each variable state vector between the status quo and the final dynamic simulation are graphed here as a relative percentage. Nature-based solutions, which are the goal variable for this system, are shown in green. 
Non-peer reviewed EarthArXiv preprint.

Under review by Environmental Science, Policy, \& Management.

\subsection{Identifying policy synergies and conflicts}

Policy analysis describes the sensitivity of the model to human interaction. By altering one (or more) of the system variables and assessing the resulting outcomes, patterns begin to emerge that reveal which policies would lead to optimal (or sub-optimal) results (Barlas, 2002). Here, the single-policy strategies were compared with the multi-policy strategies to identify areas of synergy or conflict. These concepts are defined below by Eq. 3 and Eq. 4, respectively.

Policy Synergy:

$$
\Delta S_{k j}>\sum_{i=1}^{n} \Delta S_{k i}
$$

Policy Conflict:

$$
\Delta S_{k j} \leq \bigvee_{i=1}^{n} \Delta S_{k i}
$$

where $\Delta S_{k j}$ describes the change in state vector for a strategy that combines multiple policies $(k=\mathrm{EO}, \mathrm{TT}$, $\mathrm{PP}, \mathrm{IP}, \mathrm{AL}, \mathrm{PW}, \mathrm{MT}, \mathrm{FU}, \mathrm{RE}), \Delta S_{k i}$ is the change in state vector for a single-policy strategy, and $n$ is the number of policies within each strategy.

Areas of policy synergy and conflict were then compared to the reinforcing and balancing feedback loops from the CLD to better understand the implications and to explain them as a form of causal logic, elucidated with the aid of FCM-based scenario modeling.

\section{Results and discussion}

\subsection{Characterizing human-NBS system variables}

The stakeholders nominated 26 total variables, which were optimized within Vensim to reveal 19 unique variables and 37 causal links. These results corresponded well with the average number of variables $(n=23)$ and connections ( $n=37$ ) observed in typical FCMs, according to the meta-study by Özesmi and Özesmi (2004). Interesting insights from the workshop included unique trade-offs associated with collective understanding of socio-institutional barriers compared with findings from the NBS literature (Table A1). Several key challenges were noted by the group that were not commonly observed within the NBS literature. For example, the stakeholders felt strongly that a lack of regulations and laws at the state and federal level was the strongest hindrance to local NBS implementation. Moreover, the stakeholders rejected a causal association between NBS co-benefits and improved implementation, which has been strongly linked within the NBS literature. Instead, the group suggested that local constituents are not aware of such co-benefits and are therefore more concerned with stormwater abatement characteristics than social and environmental derivatives.

Other surprising insights from the workshop included a robust debate regarding how increased vegetation within the urban fabric is considered an adverse, rather than a beneficial, impact of local NBSs. In the study region, a lack of NBS maintenance had resulted in habitat overgrowth, leading to pests, rodents, and aesthetic nuisances. Additional contradictions between the stakeholder-defined system and the NBS literature were observed, including conflicting opinions about design efficacy, community perception, political will, and institutional partnership. Such discrepancies have been identified in Fig. S1, which highlights the importance of understanding local conditions and clarifying stakeholder insights when assessing policy dynamics for complex socio-environmental issues. To aid in validating the CLD, several participants requested clarification of variable meanings and roles. Each variable was uniquely defined to represent the group's collective understanding (Table S1), which was then emailed to the stakeholders for use during the CLD validation phase. 
Non-peer reviewed EarthArXiv preprint.

Under review by Environmental Science, Policy, \& Management.

\subsection{Assessing feedback loop interactions}

The final causal loop diagram is depicted in Fig. 4. Reinforcing loops propagate the direction of change within the system, which continue to grow, "+" (or decrease, "-"), over time when a linked variable is altered. Conversely, balancing loops counteract the direction of change and transition the system toward states of equilibrium. From the CLD model, four primary reinforcing loops and two balancing loops were identified. Reinforcing loop R1 was noted as the "Maintenance Loop", whereby improved maintenance from local regulations would reduce habitat over-growth and improve community buy-in of NBS technologies, driving political will and additional regulations. Reinforcing loop R2, the "Funding Loop", was identified as an opportunity to increase NBSs by using local funds to implement more pilot projects, thereby enhancing visualization of co-benefits and strengthening community buy-in. The reinforcing loop R3, "Community Loop", describes the general stakeholder belief that enhanced external regulations would drive local regulation, negating the need for local incentives programs (which were observed to have a negative effect on community buy-in due to their volunteering nature). This, in turn, would drive local political will and trigger additional influence of federal and state governmental constructs. Reinforcing loop R4, the "Advocacy Loop", describes the condition where political will could be used to increase the amount and influence of NBS advocacy groups and local champions, thereby driving implementation of additional pilot projects, trainings, and outreach to bolster community acceptance.

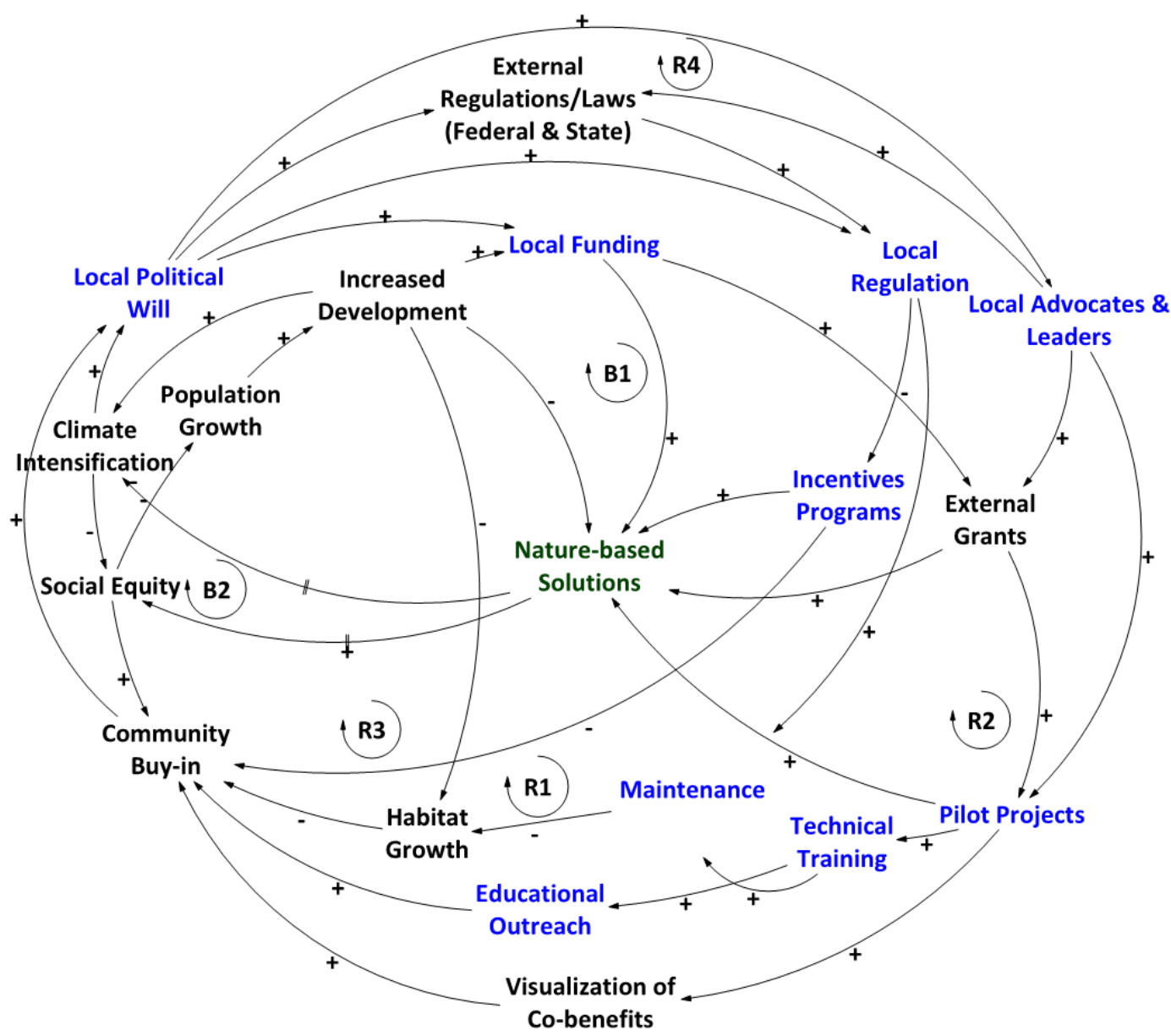

Fig. 5. Stakeholder-derived causal loop diagram depicting social-institutional factors involved with implementation of nature-based solutions. Blue = management opportunities, within the scope of stakeholder influence. Black = exogenous variables, outside the scope of stakeholder influence. Green $=$ system goal variable. Polarity of feedback loops is indicated by '+' for positive (same-direction causation) and '-' for negative (opposite-direction causation). Note: For optimal clarification, color should be maintained when printed. 
Non-peer reviewed EarthArXiv preprint.

Under review by Environmental Science, Policy, \& Management.

The balancing loop B1, "Climate Loop", was identified as an opportunity to balance the system of NBS implementation upon achieving a desirable level of climate mitigation (e.g., urban heat regulation, stormwater flow abatement, water quality enhancement, carbon sequestration), depending on local goals and conditions. The balancing loop B2, "Equity Loop", was observed as an opportunity to counteract the negative impacts of population growth and subsequent impervious development while also strengthening community buy-in. These overarching themes were used to drive the assessment of causal feedbacks and their influence on policy effectiveness, further described in Sect. 4.3.

Table 1 summarizes the feedback loops and their initial average strengths, according to Eq. 5:

$$
w_{f}^{(t=0)}= \pm \frac{\sum_{i=1}^{M} \sum_{j=1}^{M}\left|w_{i j}\right|}{M}
$$

where $w_{f}$ describes the average initial strength of each feedback loop $f$ at time $t=0, w_{i j}$ is the stakeholderdefined strength between variable $i$ and $j$, and $M$ is the total number of unique connections within the loop. The loop strength is assigned a polarity of '+' for reinforcing loops and '-' for balancing loops.

Naturally, the feedback loop weights will change during the dynamic simulation as the loops are influenced by other loops and variables over time. However, by identifying the initial feedback loop strengths according to Eq. 5, it becomes possible to complement our understanding of the FCM-based scenario results with insights regarding loop dominance, as well as shifts in loop dominance, according to how the loops inter-relate within the system.

Table 1. Summary of feedback loops identified within the stakeholder-led causal loop diagram. $R=$ reinforcing feedback loop (even number of negative connections). $\mathrm{B}=$ balancing feedback loop (odd number of negative connections). The direction of polarity and strength of each feedback is shown.

\begin{tabular}{|c|c|c|}
\hline Loop & Variable Connections & $w_{f}^{(t=0)}$ \\
\hline $\mathrm{R} 1$ & $\begin{array}{l}\text { Local Political Will } \stackrel{+0.75}{\longrightarrow} \text { Local Regulation } \stackrel{+0.50}{\longrightarrow} \text { Maintenance } \stackrel{-0.75}{\longrightarrow} \text { Habitat } \\
\text { Growth } \stackrel{-0.25}{\longrightarrow} \text { Community Buy-in } \stackrel{+0.50}{\longrightarrow} \text { Local Political Will }\end{array}$ & 0.35 \\
\hline $\mathrm{R} 2$ & $\begin{array}{l}\text { Local Political Will } \stackrel{+0.75}{\longrightarrow} \text { Local Funding } \stackrel{+0.25}{\longrightarrow} \text { External Grants } \stackrel{+0.75}{\longrightarrow} \text { Pilot } \\
\text { Projects } \stackrel{+0.50}{\longrightarrow} \text { Visualization of Co-benefits } \stackrel{+0.50}{\longrightarrow} \text { Community Buy-in } \\
\stackrel{+0.50}{\longrightarrow} \text { Local Political Will }\end{array}$ & 0.54 \\
\hline R3 & $\begin{array}{l}\text { Local Political Will } \stackrel{+0.25}{\longrightarrow} \text { External Regulations / Laws } \stackrel{+0.75}{\longrightarrow} \text { Local Regulation } \\
\stackrel{-0.25}{\longrightarrow} \text { Incentives Programs } \stackrel{-0.25}{\longrightarrow} \text { Community Buy-in } \stackrel{+0.50}{\longrightarrow} \text { Local Political Will }\end{array}$ & 0.40 \\
\hline $\mathrm{R} 4$ & $\begin{array}{l}\text { Local Political Will } \stackrel{+0.50}{\longrightarrow} \text { Local Advocates } \stackrel{+0.25}{\longrightarrow} \text { Pilot Projects } \stackrel{+0.25}{\longrightarrow} \\
\text { Technical Training } \stackrel{+0.25}{\longrightarrow} \text { Educational Outreach } \stackrel{+0.25}{\longrightarrow} \text { Community Buy-in } \\
\stackrel{+0.50}{\longrightarrow} \text { Local Political Will }\end{array}$ & 0.33 \\
\hline $\mathrm{B} 1$ & $\begin{array}{l}\text { Local Political Will } \stackrel{+0.75}{\longrightarrow} \text { Local Funding } \stackrel{+0.50}{\longrightarrow} \text { Nature-based Solutions } \stackrel{-0.50}{\longrightarrow} \\
\text { Climate Intensification } \stackrel{+0.50}{\longrightarrow} \text { Local Political Will }\end{array}$ & -0.56 \\
\hline B2 & $\begin{array}{l}\text { Social Equity } \stackrel{-0.25}{\longrightarrow} \text { Population Growth } \stackrel{+0.75}{\longrightarrow} \text { Increased Development } \stackrel{+0.25}{\longrightarrow} \\
\text { Local Funding } \stackrel{+0.25}{\longrightarrow} \text { Nature-based Solutions } \stackrel{+0.50}{\longrightarrow} \text { Social Equity }\end{array}$ & -0.40 \\
\hline
\end{tabular}

\subsection{Understanding policy with causal logic}

The dynamics of the system resulted in a positive increase in the state of the NBS variable for all of the modeled management strategies. The relative change in NBS implementation for each strategy $(n$ $=1,2,3)$ is shown in Table 2 as a percentage $\left(\Delta S_{k}\right)$. Typically, when performing FCM-based scenario modeling for policy assessment, the change in state vector for the goal variable is calculated as the difference between the baseline-scenario and the strategy-scenario. In such cases, the baseline scenario 
Non-peer reviewed EarthArXiv preprint.

Under review by Environmental Science, Policy, \& Management.

is defined as the state vector of the model when all driver variables (i.e., variables that have no input feedbacks) are clamped to a value of +1.00 (Singh and Chudasama, 2020). However, the FCM model for this study had no driver variables, meaning all variables were ordinary and contained both input and output feedbacks (Özesmi and Özesmi, 2004), therefore the baseline NBS state vector was null $\left(\Delta \mathrm{S}_{\mathrm{NBS}}=0\right)$. As such, $\Delta S_{k}$ represents the state vector value for the NBS variable after each policy, or set of policies, was modeled within the Mental Modeler scenario-builder, expressed as a percentage.

Table 2. Fuzzy cognitive mapping-based scenario output used to understand policy effectiveness on the final state change $\Delta S_{k}$ of nature-based solutions. $k=$ nomenclature of each strategy, where: Educational Outreach $=\mathrm{EO}$, Technical Training $=$ TT, Pilot Projects $=$ PP, Incentives Programs $=$ IP, Advocacy and Leadership $=$ AL, Political Will $=\mathrm{PW}$, Maintenance $=$ MT, Funding $=\mathrm{FU}$, Regulations $=\mathrm{RE}$. ' "' denotes highest effectiveness within each cohort of management strategies.

\begin{tabular}{|c|c|c|c|c|c|c|c|c|c|c|c|}
\hline \multicolumn{2}{|c|}{1 Policy $(n=1)$} & \multicolumn{2}{|c|}{2 Policies $(n=2)$} & \multicolumn{8}{|c|}{3 Policies $(n=3)$} \\
\hline$k$ & $\Delta S_{k i}$ & $k$ & $\Delta S_{k j}$ & $k$ & $\Delta S_{k j}$ & $k$ & $\Delta S_{k j}$ & $k$ & $\Delta S_{k j}$ & $k$ & $\Delta S_{k j}$ \\
\hline EO & $9 \%$ & TT-MT & $7 \%$ & EO-TT-PP & $53 \%$ & EO-PW-RE & $55 \%$ & TT-FU-RE & $63 \%$ & IP-MT-RE & $18 \%$ \\
\hline TT & $5 \%$ & TT-FU & $66 \%$ & EO-TT-IP & $24 \%$ & EO-MT-FU & $67 \%$ & PP-IP-AL & $71 \%$ & IP-FU-RE & $77 \%$ \\
\hline PP & $48 \%$ & TT-RE & $3 \%$ & EO-TT-AL & $42 \%$ & EO-MT-RE & $10 \%$ & PP-IP-PW & $86 \%$ & AL-PW-MT & $68 \%$ \\
\hline IP & $12 \%$ & PP-IP & $60 \%$ & EO-TT-PW & $56 \%$ & EO-FU-RE & $63 \%$ & PP-IP-MT & $62 \%$ & AL-PW-FU & $80 \%$ \\
\hline$A L$ & $36 \%$ & PP-AL & $60 \%$ & EO-TT-MT & $14 \%$ & TT-PP-IP & $62 \%$ & ${ }^{*}$ PP-IP-FU & $90 \%$ & $A L-P W-R E$ & $67 \%$ \\
\hline PW & $56 \%$ & PP-PW & $76 \%$ & EO-TT-FU & $67 \%$ & TT-PP-AL & $61 \%$ & PP-IP-RE & $62 \%$ & AL-MT-FU & $81 \%$ \\
\hline MT & $5 \%$ & PP-MT & $51 \%$ & EO-TT-RE & $9 \%$ & TT-PP-PW & $76 \%$ & PP-AL-PW & $79 \%$ & AL-MT-RE & $36 \%$ \\
\hline${ }^{\star} \mathrm{FU}$ & $65 \%$ & ${ }^{\star}$ PP-FU & $84 \%$ & EO-PP-IP & $64 \%$ & TT-PP-MT & $51 \%$ & PP-AL-MT & $61 \%$ & AL-FU-RE & $79 \%$ \\
\hline \multirow[t]{2}{*}{$\mathrm{RE}$} & \multirow[t]{2}{*}{$0 \%$} & PP-RE & $47 \%$ & EO-PP-AL & $63 \%$ & TT-PP-FU & $84 \%$ & PP-AL-FU & $88 \%$ & PW-MT-FU & $73 \%$ \\
\hline & & IP-AL & $50 \%$ & EO-PP-PW & $76 \%$ & TT-PP-RE & $48 \%$ & PP-AL-RE & $58 \%$ & PW-MT-RE & $55 \%$ \\
\hline \multicolumn{2}{|c|}{2 Policies $(n=2)$} & IP-PW & $74 \%$ & EO-PP-MT & $54 \%$ & TT-IP-AL & $53 \%$ & PP-PW-MT & $76 \%$ & PW-FU-RE & $72 \%$ \\
\hline$k$ & $\Delta S_{k j}$ & IP-MT & $18 \%$ & EO-PP-FU & $84 \%$ & TT-IP-PW & $64 \%$ & PP-PW-FU & $85 \%$ & MT-FU-RE & $63 \%$ \\
\hline EO-TT & $11 \%$ & IP-FU & $76 \%$ & EO-PP-RE & $50 \%$ & TT-IP-MT & $20 \%$ & PP-PW-RE & $75 \%$ & \multirow{12}{*}{$\begin{array}{l}\text { Synergy: } \\
\text { Conflict: }\end{array}$} & \\
\hline EO-PP & $52 \%$ & IP-RE & $16 \%$ & EO-IP-AL & $55 \%$ & TT-IP-FU & $77 \%$ & PP-MT-FU & $84 \%$ & & \\
\hline EO-IP & $21 \%$ & AL-PW & $68 \%$ & EO-IP-PW & $74 \%$ & TT-IP-RE & $19 \%$ & PP-MT-RE & $48 \%$ & & \\
\hline EO-AL & $41 \%$ & AL-MT & $39 \%$ & EO-IP-MT & $27 \%$ & TT-AL-PW & $68 \%$ & PP-FU-RE & $82 \%$ & & \\
\hline EO-PW & $56 \%$ & AL-FU & $81 \%$ & EO-IP-FU & $77 \%$ & TT-AL-MT & $40 \%$ & IP-AL-PW & $81 \%$ & & \\
\hline EO-MT & $13 \%$ & AL-RE & $35 \%$ & EO-IP-RE & $24 \%$ & TT-AL-FU & $81 \%$ & IP-AL-MT & $53 \%$ & & \\
\hline EO-FU & $66 \%$ & PW-MT & $56 \%$ & EO-AL-PW & $68 \%$ & TT-AL-RE & $37 \%$ & IP-AL-FU & $88 \%$ & & \\
\hline EO-RE & $8 \%$ & PW-FU & $73 \%$ & EO-AL-MT & $43 \%$ & TT-PW-MT & $56 \%$ & IP-AL-RE & $52 \%$ & & \\
\hline TT-PP & $50 \%$ & PW-RE & $55 \%$ & EO-AL-FU & $81 \%$ & TT-PW-FU & $73 \%$ & IP-PW-MT & $74 \%$ & & \\
\hline TT-IP & $18 \%$ & MT-FU & $66 \%$ & EO-AL-RE & $39 \%$ & TT-PW-RE & $42 \%$ & IP-PW-FU & $84 \%$ & & \\
\hline TT-AL & $39 \%$ & MT-RE & $2 \%$ & EO-PW-MT & $56 \%$ & TT-MT-FU & $66 \%$ & IP-PW-RE & $74 \%$ & & \\
\hline TT-PW & $56 \%$ & FU-RE & $62 \%$ & EO-PW-FU & $73 \%$ & TT-MT-RE & $4 \%$ & IP-MT-FU & $77 \%$ & & \\
\hline
\end{tabular}

Policy combinations that were synergistic, meaning they worked together to produce a greater NBS state change than had the policies been implemented in silo, are highlighted in Table 2 with light orange. Policy combinations that were conflicting, meaning they interacted to produce an NBS state vector that was less than (or equal to) that of the corresponding individual policies, are noted in green. For example, strategy PP-RE (pilot projects and local regulations) is a conflicting policy, which resulted in $\Delta \mathrm{S}_{\mathrm{PP}-\mathrm{RE}}=47 \%$. However, had pilot projects $\left(\Delta \mathrm{SPP}_{\mathrm{P}}=48 \%\right)$ been implemented as a single strategy, we observe a greater change in NBS implementation potential ( $\Delta$ SPP $>$ SPP-RE). Such results may be explained by investigating the location of PP and RE within the CLD and assessing how the feedback loops interact. Pilot projects are included in loop 
Non-peer reviewed EarthArXiv preprint.

Under review by Environmental Science, Policy, \& Management.

$\mathrm{R} 2$ (Funding Loop, $\mathrm{W}_{\mathrm{R} 2}=0.54$ ) and $\mathrm{R} 4$ (Advocacy Loop, $\mathrm{W}_{\mathrm{R} 4}=0.33$ ), whereas local regulations are impacted by loop R1 (Maintenance Loop, $W_{R 1}=0.35$ ) and R3 (Community Loop, $W_{R 3}=0.40$ ). The initial strength of the interacting loops for $\mathrm{PP}$ ( $\mathrm{WR}_{\mathrm{R} 2+\mathrm{R} 4=0.87)}$ is much greater than the initial strength of the interacting RE loops $\left(W_{R 1+R 3=0.70)}\right.$. As such, the combination of these policies would not produce a greater end-result after dynamic simulation of the clamped variables, and it could be concluded that implementing the RE policy is not an optimal use of resources.

A similar investigation is used here to explain policy synergy. For example, the combined strategy IP$\mathrm{PW}$ resulted in a state change of $\Delta \mathrm{S}_{\mathrm{IP}-\mathrm{PW}}=74 \%$. Had each of these policies been implemented at separate times, and the dynamic interactions not considered, the NBS state would only be $68 \%$ $\left(\Delta S_{\mathrm{P}}=12 \%+\Delta \mathrm{S}_{\mathrm{PW}}=56 \%\right)$. In checking the corresponding feedback loops, IP is only included within $\mathrm{R} 3$

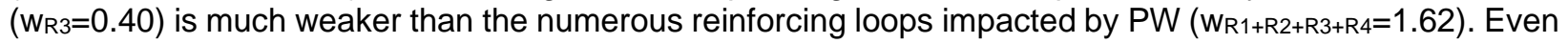
when consider the balancing effects of loop B1 on political will ( $\left.W_{B 1}=-0.56\right)$, it becomes clear that combing the PW policy with the IP policy results in stronger system dynamic change.

While such manual interpretations of all policy combinations and feedback loops within the system would quickly become burdensome, the proposed CLD+FCM-based scenario approach presented here provides a rapid assessment of how strategies may interact within the system dynamics to produce synergy or conflict. Similar insights may be derived, for example, by ranking the final NBS state vectors (i.e., the $\Delta S_{k}$ values) and noting the occurrence of variables, as shown in Table 3. The local funding (FU) variable is present within almost all of the highest-efficiency strategies (i.e., upper quartile). The political will (PW) variable is highly representative within the top-half of strategies, while the only instances of PW within the bottom-half are indeed those combinations that were identified as policy conflicts. In exploring the interaction of associated feedback loops, FU is a component of both the strong balancing loop B1 and the strong reinforcing loop $\mathrm{R} 1$, which may have trended the system toward equilibrium had there been no other dynamic forces involved. However, loop R1 triggers each of the additional reinforcing loops, thereby amplifying total systematic change. This causal logic also explains why pilot projects (PP) and political will (PW) are highly associated with greater NBS impact in the system. Other system variables that interacted with balancing loop B1, but which did not have the added reinforcement from loops R2 and R3 to counteract the balancing forces, showcased less favorable outcomes and often policy conflict.

Table 3. Rank of management strategies $(k)$ and their corresponding NBS end-state vector values $\left(S_{k}\right)$, describing the efficacy of policy combinations toward furthering implementation of nature-based solutions in the case study model.

\begin{tabular}{|c|c|c|c|c|c|c|c|c|}
\hline \multirow[b]{2}{*}{ No. } & \multicolumn{2}{|c|}{ Upper Quartile (Q3) } & \multicolumn{4}{|c|}{ Middle Quartile (Q2) } & \multicolumn{2}{|c|}{ Lower Quartile (Q1) } \\
\hline & $\begin{array}{l}\text { Strategy } \\
(k)\end{array}$ & $\begin{array}{l}\text { Efficacy } \\
\left(\Delta S_{k}\right), \%\end{array}$ & $\begin{array}{l}\text { Strategy } \\
(k)\end{array}$ & $\begin{array}{l}\text { Efficacy } \\
\left(\Delta S_{k}\right), \%\end{array}$ & $\begin{array}{c}\text { Strategy } \\
(k)\end{array}$ & $\begin{array}{l}\text { Efficacy } \\
\left(\Delta S_{k}\right), \%\end{array}$ & $\begin{array}{c}\text { Strategy } \\
(k)\end{array}$ & $\begin{array}{l}\text { Efficacy } \\
\left(\Delta S_{k}\right), \%\end{array}$ \\
\hline 1 & PP-IP-FU & $90 \%$ & EO-IP-PW & $74 \%$ & TT-PP-AL & $61 \%$ & EO-TT-AL & $42 \%$ \\
\hline 2 & PP-AL-FU & $88 \%$ & IP-PW-MT & $74 \%$ & PP-AL-MT & $61 \%$ & TT-PW-RE & $42 \%$ \\
\hline 3 & IP-AL-FU & $88 \%$ & IP-PW-RE & $74 \%$ & PP-IP & $60 \%$ & EO-AL & $41 \%$ \\
\hline 4 & PP-IP-PW & $86 \%$ & PW-FU & $73 \%$ & PP-AL & $60 \%$ & TT-AL-MT & $40 \%$ \\
\hline 5 & PP-PW-FU & $85 \%$ & EO-PW-FU & $73 \%$ & PP-AL-RE & $58 \%$ & TT-AL & $39 \%$ \\
\hline 6 & PP-FU & $84 \%$ & TT-PW-FU & $73 \%$ & EO-PW & $56 \%$ & AL-MT & $39 \%$ \\
\hline 7 & EO-PP-FU & $84 \%$ & PW-MT-FU & $73 \%$ & TT-PW & $56 \%$ & EO-AL-RE & $39 \%$ \\
\hline 8 & TT-PP-FU & $84 \%$ & PW-FU-RE & $72 \%$ & PW-MT & $56 \%$ & TT-AL-RE & $37 \%$ \\
\hline 9 & PP-MT-FU & $84 \%$ & PP-IP-AL & $71 \%$ & EO-TT-PW & $56 \%$ & AL-MT-RE & $36 \%$ \\
\hline 10 & IP-PW-FU & $84 \%$ & AL-PW & $68 \%$ & EO-PW-MT & $56 \%$ & $A L-R E$ & $35 \%$ \\
\hline 11 & PP-FU-RE & $82 \%$ & EO-AL-PW & $68 \%$ & TT-PW-MT & $56 \%$ & EO-IP-MT & $27 \%$ \\
\hline 12 & AL-FU & $81 \%$ & TT-AL-PW & $68 \%$ & PW-RE & $55 \%$ & EO-TT-IP & $24 \%$ \\
\hline 13 & EO-AL-FU & $81 \%$ & AL-PW-MT & $68 \%$ & EO-IP-AL & $55 \%$ & EO-IP-RE & $24 \%$ \\
\hline 14 & TT-AL-FU & $81 \%$ & EO-TT-FU & $67 \%$ & EO-PW-RE & $55 \%$ & EO-IP & $21 \%$ \\
\hline 15 & IP-AL-PW & $81 \%$ & EO-MT-FU & $67 \%$ & PW-MT-RE & $55 \%$ & TT-IP-MT & $20 \%$ \\
\hline 16 & AL-MT-FU & $81 \%$ & AL-PW-RE & $67 \%$ & EO-PP-MT & $54 \%$ & TT-IP-RE & $19 \%$ \\
\hline 17 & AL-PW-FU & $80 \%$ & EO-FU & $66 \%$ & EO-TT-PP & $53 \%$ & TT-IP & $18 \%$ \\
\hline 18 & PP-AL-PW & $79 \%$ & TT-FU & $66 \%$ & TT-IP-AL & $53 \%$ & IP-MT & $18 \%$ \\
\hline 19 & AL-FU-RE & $79 \%$ & MT-FU & $66 \%$ & IP-AL-MT & $53 \%$ & IP-MT-RE & $18 \%$ \\
\hline 20 & EO-IP-FU & $77 \%$ & TT-MT-FU & $66 \%$ & EO-PP & $52 \%$ & IP-RE & $16 \%$ \\
\hline 21 & TT-IP-FU & $77 \%$ & EO-PP-IP & $64 \%$ & IP-AL-RE & $52 \%$ & EO-TT-MT & $14 \%$ \\
\hline 22 & IP-MT-FU & $77 \%$ & TT-IP-PW & $64 \%$ & PP-MT & $51 \%$ & EO-MT & $13 \%$ \\
\hline 23 & IP-FU-RE & $77 \%$ & EO-PP-AL & $63 \%$ & TT-PP-MT & $51 \%$ & EO-TT & $11 \%$ \\
\hline
\end{tabular}


Non-peer reviewed EarthArXiv preprint.

Under review by Environmental Science, Policy, \& Management.

\begin{tabular}{lllllllll}
24 & PP-PW & $76 \%$ & EO-FU-RE & $63 \%$ & TT-PP & $50 \%$ & EO-MT-RE & $10 \%$ \\
25 & IP-FU & $76 \%$ & TT-FU-RE & $63 \%$ & IP-AL & $50 \%$ & EO-TT-RE & $9 \%$ \\
26 & EO-PP-PW & $76 \%$ & MT-FU-RE & $63 \%$ & EO-PP-RE & $50 \%$ & EO-RE & $8 \%$ \\
27 & TT-PP-PW & $76 \%$ & FU-RE & $62 \%$ & TT-PP-RE & $48 \%$ & TT-MT & $7 \%$ \\
28 & PP-PW-MT & $76 \%$ & TT-PP-IP & $62 \%$ & PP-MT-RE & $48 \%$ & TT-MT-RE & $4 \%$ \\
29 & PP-PW-RE & $75 \%$ & PP-IP-MT & $62 \%$ & PP-RE & $47 \%$ & TT-RE & $3 \%$ \\
30 & IP-PW & $74 \%$ & PP-IP-RE & $62 \%$ & EO-AL-MT & $43 \%$ & MT-RE & $2 \%$ \\
\hline
\end{tabular}

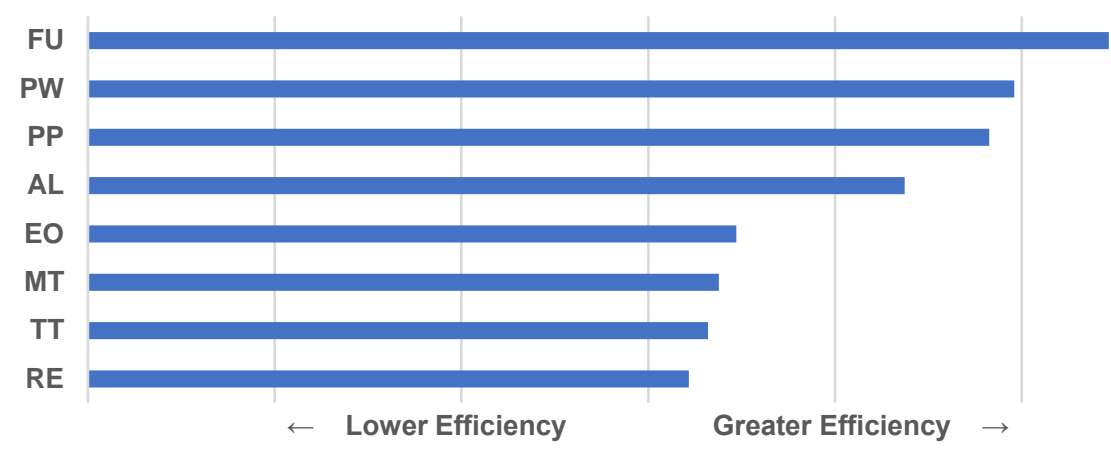

Fig. 6. Relative difference for individual variables toward system efficiency, where the system goal is increasing the NBS end-state vector. Educational Outreach $=E O$, Technical Training $=$ TT, Pilot Projects $=$ PP, Incentives Programs $=I P$, Advocacy and Leadership $=$ AL, Political Will $=$ PW, Maintenance $=$ MT, Funding $=$ FU, Regulations $=$ RE .

Fig. 6 demonstrates the relative efficiency of management variables by summing the $\Delta S_{k}$ values for each corresponding $k$. RE, TT, and MT exhibit weak efficiencies when combined with other policy options. An assessment of the associated feedback loops (which are color-coded in Appendix Fig. A2 for improved visualization) demonstrates how these variables are each located on only one feedback loop, thereby triggering less change and momentum in the overall system trajectory than those variables that are leveraged at the intersection of many overlapping loops.

\section{Conclusion}

Environmental problems and their solutions are complex in nature and are often further challenged by social and institutional constructs that are not well-understood. A key issue in mitigating such factors and designing effective policies includes the inability to examine a range of dynamic system trajectories, state changes, and feedback loops for alternative futures. Moreover, policy-making with limited resources and external influences require an understanding of emergent system behavior for optimal coupling of unique management strategies. A shift in one system variable could trigger self-regulating interactions and/or divergent outcomes elsewhere, depending on the structure of the model and their connective strengths. This study highlights how identifying the nature of the system must be supplemented by also identifying the social context within which the system is embedded, demonstrated here through a case study of NBSs as a complex human-environmental phenomena.

Mainstreaming NBSs into urban agendas is a key challenge that must be overcome in order to realize global climate goals (UNEP, 2019), which necessitates understanding the human feedbacks within the system to identify transition variables that, if strengthened, could improve implementation. As challenged by the UN IPCC, inclusion of social influences in our NBS planning paradigms would improve the efficacy of our management objectives (Frantzeskaki et al., 2019). This research schematized interactions within a complex human-NBS system according to loops and linkages derived from real-world stakeholder input. A holistic approach to systems-thinking provided a means for describing complex behavior and assessing the relative effectiveness of various management strategies in NBS planning.

The initial stages of systems-thinking capture the overall concept of a system from stakeholder knowledge by representing key variables and their interrelationships. An analysis of the resulting feedback loops explains how the system responds to change in a resistant or complementary manner. Policy conflict and synergy stems from these underlying mechanisms that are often difficult to disentangle visually, even at simple scales. Instead, incorrect assessments of interacting feedback loops may lead to the failure of 
Non-peer reviewed EarthArXiv preprint.

Under review by Environmental Science, Policy, \& Management.

systematic learning and undermine implementation of the most beneficial policies. As systems increase in complexity, computer-based simulations are often necessary to understand how interventions alter the state of the system. Simulation modeling enhances our ability to elicit insights from complex systems by capturing long-term accumulation processes and trajectory shifts. However, SDM-based simulations are typically conducted using data-intensive dynamic models (e.g., SFDs), which are not always feasible when considering human-environmental feedbacks. FCM-based scenario-building is a practical tool for simulating CLD systems by assigning a degree of influence between components, clamping plausible variables, and assessing changes to the goal element (Gray et al., 2014). This approach assigns meaning to processes that are otherwise difficult to compute by leveraging knowledge embedded within stakeholder experiences and their previous interactions with the system.

A benefit of transposing CLDs into FCMs involves the mathematical foundation of FCMs in graph theory, which provides a computationally-efficient method for rapidly simulating system trajectories. Although coupled CLD-FCM modeling has been demonstrated in the literature (Coletta et al., 2021; Giordano et al., 2020, 2007; Shahvi et al., 2021), it is not commonly used to assess social interactions in policy-making. To transition toward management-oriented research for socio-environmental phenomena, this study encourages the coupling of traditional SDM approaches (e.g., GMB, CLD), which identify the nature of the system, with FCM-based scenarios, which simulate the structure of the system. By integrating qualitative and semi-quantitative modeling, this approach reveals systemic interactions that would not be clear from CLD or FCM alone, but which also do not require complex modeling with robust datasets. Instead, empirical data for weighted connections may be elicited from the stakeholders at the same time as the GMB session. Such an interactive process transforms elusive systematic barriers into a broad vision of new and adaptive management opportunities.

Several major synergies and tradeoffs associated with NBS implementation, which had hitherto been studied as a series of siloed challenges, were revealed by combining the strengths of system dynamics with cognitive mapping. This integrative approach enriches the theoretical merging of systems-thinking epistemology (i.e., embedding human cognition within the system), with ontology (i.e., using the underling structure of the system to elicit insights). In summary, feedbacks and adaptations amongst complex humanenvironmental systems must be understood and explicitly accounted for in order to optimize system-wide sustainability with limited resources. The vision for the future is that we will approach human-environmental problems as a web of interlinked connections with weighted interdependencies through the lens of systemsthinking, thereby providing a mechanism based on human reality to better understand management actions within a rapidly changing world. 
Non-peer reviewed EarthArXiv preprint.

Under review by Environmental Science, Policy, \& Management.

\section{Appendix}

Table A.1. Summary of literature review identifying key socio-institutional barriers to widespread NBS adoption and implementation.

\begin{tabular}{|c|c|c|c|}
\hline Theme & Variable & References & Key Considerations \\
\hline \multirow{3}{*}{ 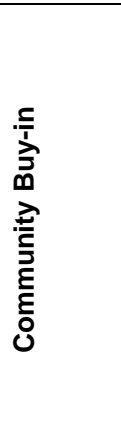 } & $\begin{array}{l}\text { Economic } \\
\text { Incentives }\end{array}$ & $\begin{array}{l}\text { (Baptiste et al., 2015; Tayouga and } \\
\text { Gagné, 2016; Vogel et al., 2015) }\end{array}$ & $\begin{array}{l}\text { Subsidies, grants, loans, fee reductions. } \\
\text { Incorporated into local development plants. } \\
\text { Drainage tax/fee reduction for individual residents. } \\
\text { Federal subsidy programs. }\end{array}$ \\
\hline & $\begin{array}{l}\text { Educational } \\
\text { Opportunities }\end{array}$ & $\begin{array}{l}\text { (Chaffin et al., 2016; Derkzen et al., } \\
\text { 2017; Solheim et al., 2021; Thorne et } \\
\text { al., 2018) }\end{array}$ & $\begin{array}{l}\text { Community perceptions and understanding of NBS } \\
\text { functionality and benefits, as well as costs. Outreach } \\
\text { programs. Media reporting. }\end{array}$ \\
\hline & $\begin{array}{l}\text { Public } \\
\text { Participation }\end{array}$ & $\begin{array}{l}\text { (Baptiste et al., 2015; Bissonnette et al., } \\
\text { 2018; Cohen-Shacham et al., 2019; } \\
\text { Dhakal and Chevalier, 2017; Santoro et } \\
\text { al., 2019; Wamsler et al., 2020; Zuniga- } \\
\text { Teran et al., 2020) }\end{array}$ & $\begin{array}{l}\text { Adaptive governance structure. Targeted and } \\
\text { strategic citizen involvement in selection and } \\
\text { planning process, funding, increasing public } \\
\text { awareness. Neighborhood workshops. Dialogue } \\
\text { with civil groups. Targeted media outlets. }\end{array}$ \\
\hline \multirow{3}{*}{$\begin{array}{l}\frac{0}{3} \\
\frac{1}{3} \\
\frac{0}{0} \\
\frac{\pi}{0} \\
\text { c }\end{array}$} & Cultural Values & $\begin{array}{l}\text { (Derkzen et al., 2017; Solheim et al., } \\
\text { 2021; Thorne et al., 2018) }\end{array}$ & $\begin{array}{l}\text { Traditional versus progressive engineering culture. } \\
\text { Public perception shift. Fear of perceived risk to } \\
\text { change. Lack of sense of urgency to addressing } \\
\text { climate change. }\end{array}$ \\
\hline & $\begin{array}{l}\text { Equitable } \\
\text { Resilience } \\
\text { Strategy }\end{array}$ & $\begin{array}{l}\text { (Derkzen et al., 2017; Zuniga-Teran et } \\
\text { al., 2020) }\end{array}$ & $\begin{array}{l}\text { Capacitance building in vulnerable and marginalized } \\
\text { communities with reference to NBSs. }\end{array}$ \\
\hline & Co-benefits & $\begin{array}{l}\text { (O’Donnell et al., 2017; Ramírez- } \\
\text { Agudelo et al., 2020; Solheim et al., } \\
\text { 2021) }\end{array}$ & $\begin{array}{l}\text { Clear identification of co-benefits to support shared } \\
\text { set of values and community support. Long-term } \\
\text { focus on co-benefits. }\end{array}$ \\
\hline \multirow{3}{*}{ 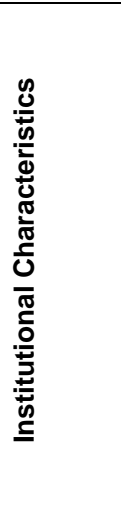 } & Fragmentation & $\begin{array}{l}\text { (Chaffin et al., 2016; Ellis and Lundy, } \\
\text { 2016; Kabisch et al., 2016; Ramírez- } \\
\text { Agudelo et al., 2020; Solheim et al., } \\
\text { 2021; Vásquez et al., 2016; Wamsler et } \\
\text { al., 2020; Zuniga-Teran et al., 2020) }\end{array}$ & $\begin{array}{l}\text { Central, singular NBS department. Integrated } \\
\text { across sectors, separate from other utilities. } \\
\text { Transverses multiple jurisdictions. Interagency } \\
\text { work. Active cohesion. }\end{array}$ \\
\hline & Financing & $\begin{array}{l}\text { (Li et al., 2017; McRae, 2016; } \\
\text { O'Donnell et al., 2017; Solheim et al., } \\
\text { 2021; Thorne et al., 2018; Zuniga- } \\
\text { Teran et al., 2020) }\end{array}$ & $\begin{array}{l}\text { Understanding cost comparison to grey- } \\
\text { infrastructure. Quantification of co-benefits. } \\
\text { Combined funding sources. Adequate economic } \\
\text { resources. Competing priorities. }\end{array}$ \\
\hline & $\begin{array}{l}\text { Regulatory } \\
\text { Frameworks }\end{array}$ & $\begin{array}{l}\text { (Dhakal and Chevalier, 2016; } \\
\text { Gersonius et al., 2016; Levy et al., } \\
\text { 2014; O'Donnell et al., 2017; Sarabi et } \\
\text { al., 2020; Solheim et al., 2021) }\end{array}$ & $\begin{array}{l}\text { Less stringent than grey-water, improves costs and } \\
\text { implementation. Defined legal standards. } \\
\text { Thresholds to trigger NBS stormwater management. } \\
\text { Confusion/conflicting provisions. Regulations } \\
\text { regarding long-term maintenance requirements. }\end{array}$ \\
\hline \multirow{4}{*}{ 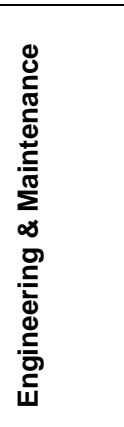 } & $\begin{array}{l}\text { Design } \\
\text { Standards }\end{array}$ & $\begin{array}{l}\text { (Kronenberg, 2015; Solheim et al., } \\
\text { 2021; Zuniga-Teran et al., 2020) }\end{array}$ & $\begin{array}{l}\text { Uncertainties regarding how NBSs work locally. } \\
\text { Technical manuals. Spatial planning guidelines. }\end{array}$ \\
\hline & $\begin{array}{l}\text { Technical } \\
\text { Experience }\end{array}$ & $\begin{array}{l}\text { (Li et al., 2017; O’Donnell et al., 2017; } \\
\text { Solheim et al., 2021; Wamsler et al., } \\
\text { 2020; Zuniga-Teran et al., 2020) }\end{array}$ & $\begin{array}{l}\text { History of past project success. Certified expertise. } \\
\text { Workshops and trainings. Staff turnover of NBS } \\
\text { expertise. }\end{array}$ \\
\hline & Maintainability & $\begin{array}{l}\text { (Kabisch et al., 2016; Li et al., 2017; } \\
\text { Ramírez-Agudelo et al., 2020; Thorne } \\
\text { et al., 2018) }\end{array}$ & $\begin{array}{l}\text { Regular inspections, monitoring guidelines. Cost of } \\
\text { regular maintenance (diversified responsibility). } \\
\text { Low-maintenance design options. }\end{array}$ \\
\hline & Pilot Projects & $\begin{array}{l}\text { (Li et al., 2017, 2018; Zuniga-Teran et } \\
\text { al., 2020) }\end{array}$ & $\begin{array}{l}\text { Political leadership and champions. Successful } \\
\text { community pilot projects (tours, educational } \\
\text { signage, press coverage). }\end{array}$ \\
\hline
\end{tabular}


Non-peer reviewed EarthArXiv preprint.

Under review by Environmental Science, Policy, \& Management.

Table A.2. Local stakeholder titles and jurisdictional domains involved in the group model-building session for elucidating barriers and management opportunities between humans and nature-based solutions.

\begin{tabular}{|c|c|c|c|}
\hline Domain & Name: Institution & Role & NBS Experience \\
\hline Local & $\begin{array}{l}\text { Rachel Powers: } \\
\text { Citizens Environmental } \\
\text { Coalition }\end{array}$ & $\begin{array}{l}\text { Community } \\
\text { Engagement }\end{array}$ & $\begin{array}{l}\text { Environmental coalitions and local communication of grassroots } \\
\text { efforts. } \\
\qquad \begin{array}{l}\checkmark \\
\checkmark\end{array} \\
\checkmark \text { Contributor, Houston Climate Action Plan } \\
\end{array}$ \\
\hline Local & $\begin{array}{l}\text { Houston Arboretum \& } \\
\text { Nature Center }\end{array}$ & Ecological Expertise & $\begin{array}{l}\text { Conservation leadership of local ecological restoration and nature- } \\
\text { based practice. }\end{array}$ \\
\hline Local & $\begin{array}{l}\text { Walter P. Moore \& } \\
\text { Associates, Inc. }\end{array}$ & Civil Engineering & $\begin{array}{l}\text { Engineering for design and construction of numerous NBS projects } \\
\text { throughout greater-Houston region. }\end{array}$ \\
\hline \multirow{5}{*}{ Local } & \multirow{5}{*}{$\begin{array}{l}\text { Michael F. Bloom, } \\
\text { P.E., ENV SP, CFM: } \\
\text { R.G. Miller Engineers, } \\
\text { Inc. }\end{array}$} & \multirow{5}{*}{$\begin{array}{l}\text { Environmental } \\
\text { Engineering }\end{array}$} & $\begin{array}{l}\text { Sustainability consulting expert and engineer for numerous NBS } \\
\text { projects, involving a variety of community builders. }\end{array}$ \\
\hline & & & $\begin{array}{l}\checkmark \quad \text { Author, Harris County Residential Green Infrastructure } \\
\text { Standards - Imagination Zones }\end{array}$ \\
\hline & & & Author, Houston Incentives for Green Development \\
\hline & & & $\begin{array}{l}\checkmark \quad \text { Member, Harris County Community Flood } \\
\text { Resilience Task Force }\end{array}$ \\
\hline & & & $\checkmark \quad$ Member, Houston Drainage Task Force \\
\hline \multirow[t]{2}{*}{ Municipal } & \multirow{2}{*}{ City of Houston } & \multirow{2}{*}{$\begin{array}{l}\text { Drainage Planning: } \\
\text { Public Works }\end{array}$} & $\begin{array}{l}\text { Rehabilitation, construction, and planning of water resources and } \\
\text { environmental projects throughout Houston. }\end{array}$ \\
\hline & & & $\checkmark \quad$ Resilient Houston Strategy \\
\hline \multirow[t]{2}{*}{ Municipal } & \multirow[t]{2}{*}{ City of Houston } & \multirow[t]{2}{*}{$\begin{array}{l}\text { Infrastructure } \\
\text { Maintenance }\end{array}$} & $\begin{array}{l}\text { Maintenance of public works facilities, including green } \\
\text { development. }\end{array}$ \\
\hline & & & $\begin{array}{l}\text { Trans-disciplinary resilience-building efforts for region, including } \\
\text { natural disasters, infrastructure, and social inequality. }\end{array}$ \\
\hline \multirow[t]{3}{*}{ Municipal } & \multirow[t]{3}{*}{ City of Houston } & \multirow{3}{*}{$\begin{array}{l}\text { Sustainability \& } \\
\text { Recovery Planning }\end{array}$} & $\checkmark \quad$ Houston Climate Action Plan \\
\hline & & & Resilient Houston Strategy \\
\hline & & & Incentives for Green Development \\
\hline \multirow{2}{*}{ Regional } & \multirow{2}{*}{$\begin{array}{l}\text { Harris County Flood } \\
\text { Control District }\end{array}$} & \multirow{2}{*}{ Stormwater Planning } & $\begin{array}{l}\text { Regional drainage planning for county, including stormwater } \\
\text { conveyance and quality for NBS projects. }\end{array}$ \\
\hline & & & $\begin{array}{l}\checkmark \quad \text { Harris County Low Impact Development Infrastructure } \\
\text { Design Criteria }\end{array}$ \\
\hline \multirow{3}{*}{ Regional } & \multirow{3}{*}{$\begin{array}{l}\text { Harris County } \\
\text { Engineering }\end{array}$} & \multirow{3}{*}{$\begin{array}{l}\text { Public Works } \\
\text { Planning }\end{array}$} & $\begin{array}{l}\text { County engineering and planning for regional low-impact } \\
\text { development and green infrastructure projects. }\end{array}$ \\
\hline & & & $\begin{array}{l}\text { Harris County Low Impact Development Infrastructure } \\
\text { Design Criteria }\end{array}$ \\
\hline & & & Houston Drainage Task Force \\
\hline
\end{tabular}


Non-peer reviewed EarthArXiv preprint.

Under review by Environmental Science, Policy, \& Management.

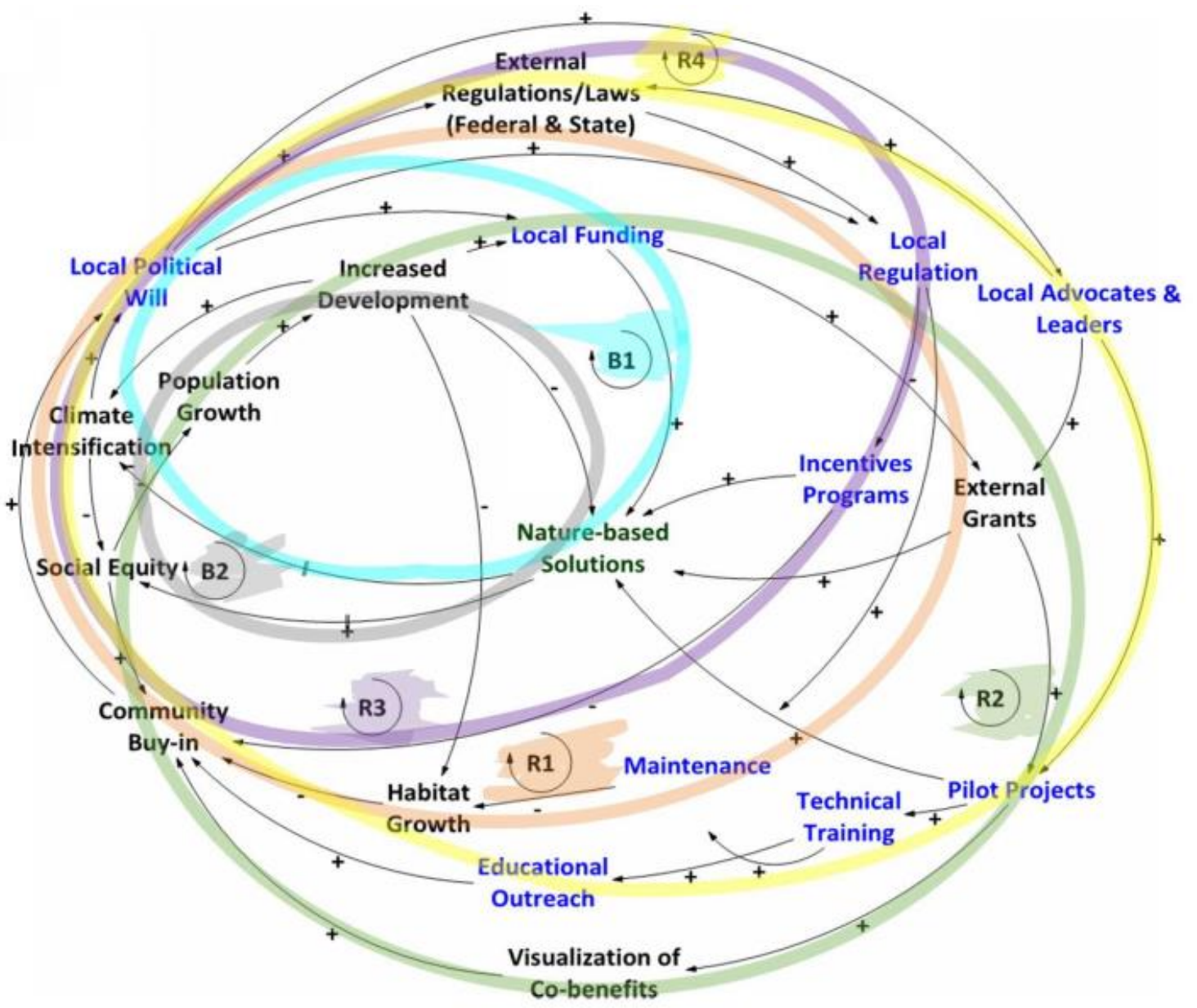

Fig. A.1. Feedback loops in causal diagram, delineated by color, presented for ease of visualization while reading and considering the impact of causal logic on policy effectiveness. Note: Color should be maintained when printed. 
Non-peer reviewed EarthArXiv preprint.

Under review by Environmental Science, Policy, \& Management.

\section{References}

Agyepong, I.A., Kodua, A., Adjei, S., Adam, T., 2012. When "solutions of yesterday become problems of today": Crisis-ridden decision making in a complex adaptive system (CAS) - The Additional Duty Hours Allowance in Ghana. Health Policy Plan. 27. https://doi.org/10.1093/heapol/czs083

Aho, M., Sarkozy-Banoczy, S., 2020. Resilient Houston.

Allen, P.M., 1988. Dynamic models of evolving systems. Syst. Dyn. Rev. 4. https://doi.org/10.1002/sdr.4260040107

Andersen, D.F., Richardson, G.P., 1997. Scripts for group model building. https://doi.org/10.1002/(sici)10991727(199722)13:2<107::aid-sdr120>3.0.co;2-7

ASCE, 2020. Stormwater Infrastructure Report Card 2020.

Axelrod, R., 1976. Structure of decision: The cognitive maps of political elites, Structure of Decision: The Cognitive Maps of Political Elites. https://doi.org/10.2307/2616237

Bahri, M., 2020. Analysis of the water, energy, food and land nexus using the system archetypes: A case study in the Jatiluhur reservoir, West Java, Indonesia. Sci. Total Environ. 716. https://doi.org/10.1016/j.scitotenv.2020.137025

Baptiste, A.K., Foley, C., Smardon, R., 2015. Understanding urban neighborhood differences in willingness to implement green infrastructure measures: A case study of Syracuse, NY. Landsc. Urban Plan. 136. https://doi.org/10.1016/j.landurbplan.2014.11.012

Barlas, Y., 2002. System Dynamics: systemic feedback modeling for policy analysis. Knowl. Sustain. Dev. An Insight into Encycl. Life Support Syst.

Bissonnette, J.F., Dupras, J., Messier, C., Lechowicz, M., Dagenais, D., Paquette, A., Jaeger, J.A.G., Gonzalez, A., 2018. Moving forward in implementing green infrastructures: Stakeholder perceptions of opportunities and obstacles in a major North American metropolitan area. Cities 81. https://doi.org/10.1016/j.cities.2018.03.014

Bloom, M.F., Asakura, K., Clements, J., Valderrama, A., 2019. Houston Incentives for Green Development.

Brennan, L.K., Sabounchi, N.S., Kemner, A.L., Hovmand, P., 2015. Systems thinking in 49 communities related to healthy eating, active living, and childhood obesity. J. Public Health Manag. Pract. 21. https://doi.org/10.1097/PHH.0000000000000248

Bureš, V., 2017. A method for simplification of complex group causal loop diagrams based on endogenisation, encapsulation and order-oriented reduction. Systems 5. https://doi.org/10.3390/systems5030046

Bureš, V., Otčenášková, T., Zanker, M., Nehéz, M., 2020. The most common issues in development of causal-loop diagrams and stock-and-flow diagrams. Int. J. Intell. Eng. Informatics 8. https://doi.org/10.1504/ijiei.2020.115722

Chaffin, B.C., Shuster, W.D., Garmestani, A.S., Furio, B., Albro, S.L., Gardiner, M., Spring, M.L., Green, O.O., 2016. A tale of two rain gardens: Barriers and bridges to adaptive management of urban stormwater in Cleveland, Ohio. J. Environ. Manage. 183. https://doi.org/10.1016/j.jenvman.2016.06.025

City of Houston, 2020. Houston Climate Action Plan.

Cohen-Shacham, E., Andrade, A., Dalton, J., Dudley, N., Jones, M., Kumar, C., Maginnis, S., Maynard, S., Nelson, C.R., Renaud, F.G., Welling, R., Walters, G., 2019. Core principles for successfully implementing and upscaling Nature-based Solutions. Environ. Sci. Policy. https://doi.org/10.1016/j.envsci.2019.04.014

Coletta, V.R., Pagano, A., Pluchinotta, I., Fratino, U., Scrieciu, A., Nanu, F., Giordano, R., 2021. Causal Loop Diagrams for supporting Nature Based Solutions participatory design and performance assessment. J. Environ. Manage. 280. https://doi.org/10.1016/j.jenvman.2020.111668

Collins, R.D., de Neufville, R., Claro, J., Oliveira, T., Pacheco, A.P., 2013. Forest fire management to avoid unintended consequences: A case study of Portugal using system dynamics. J. Environ. Manage. 130. https://doi.org/10.1016/j.jenvman.2013.08.033

de Gooyert, V., Rouwette, E., van Kranenburg, H., Freeman, E., van Breen, H., 2016. Sustainability transition dynamics: Towards overcoming policy resistance. Technol. Forecast. Soc. Change 111. https://doi.org/10.1016/j.techfore.2016.06.019

Demuzere, M., Orru, K., Heidrich, O., Olazabal, E., Geneletti, D., Orru, H., Bhave, A.G., Mittal, N., Feliu, E., Faehnle, M., 2014. Mitigating and adapting to climate change: Multi-functional and multi-scale assessment of green urban infrastructure. J. Environ. Manage. 146. https://doi.org/10.1016/j.jenvman.2014.07.025

Derkzen, M.L., van Teeffelen, A.J.A., Verburg, P.H., 2017. Green infrastructure for urban climate adaptation: How do residents' views on climate impacts and green infrastructure shape adaptation preferences? Landsc. Urban Plan. 157. https://doi.org/10.1016/j.landurbplan.2016.05.027

Dhakal, K.P., Chevalier, L.R., 2017. Managing urban stormwater for urban sustainability: Barriers and policy solutions for green infrastructure application. J. Environ. Manage. 203. https://doi.org/10.1016/j.jenvman.2017.07.065

Dhakal, K.P., Chevalier, L.R., 2016. Urban Stormwater Governance: The Need for a Paradigm Shift. Environ. Manage. 57. https://doi.org/10.1007/s00267-016-0667-5

Eberlein, R.L., Peterson, D.W., 1992. Understanding models with Vensim ${ }^{\top M}$. Eur. J. Oper. Res. 59. https://doi.org/10.1016/03772217(92)90018-5

Ellis, J.B., Lundy, L., 2016. Implementing sustainable drainage systems for urban surface water management within the regulatory framework in England and Wales. J. Environ. Manage. 183. https://doi.org/10.1016/j.jenvman.2016.09.022

Forrester, J.W., 1994. System dynamics, systems thinking, and soft OR. Syst. Dyn. Rev. 10. https://doi.org/10.1002/sdr.4260100211

Frantzeskaki, N., McPhearson, T., Collier, M.J., Kendal, D., Bulkeley, H., Dumitru, A., Walsh, C., Noble, K., Van Wyk, E., Ordóñez, 
Non-peer reviewed EarthArXiv preprint.

Under review by Environmental Science, Policy, \& Management.

C., Oke, C., Pintér, L., 2019. Nature-based solutions for urban climate change adaptation: Linking science, policy, and practice communities for evidence-based decision-making. Bioscience 69. https://doi.org/10.1093/biosci/biz042

Gebrai, Y., Ghebremichael, K., Mihelcic, J.R., 2021. A systems approach to analyzing food, energy, and water uses of a multifunctional crop: A review. Sci. Total Environ. https://doi.org/10.1016/j.scitotenv.2021.148254

Gersonius, B., van Buuren, A., Zethof, M., Kelder, E., 2016. Resilient flood risk strategies: Institutional preconditions for implementation. Ecol. Soc. 21. https://doi.org/10.5751/ES-08752-210428

Giordano, R., Mysiak, J., Raziyeh, F., Vurro, M., 2007. An integration between cognitive map and causal loop diagram for knowledge structuring in river basin management. 1st Int. Conf. Adapt. Integr. Water Manag.

Giordano, R., Pluchinotta, I., Pagano, A., Scrieciu, A., Nanu, F., 2020. Enhancing nature-based solutions acceptance through stakeholders' engagement in co-benefits identification and trade-offs analysis. Sci. Total Environ. 713. https://doi.org/10.1016/j.scitotenv.2020.136552

Gómez Martín, E., Giordano, R., Pagano, A., van der Keur, P., Máñez Costa, M., 2020. Using a system thinking approach to assess the contribution of nature based solutions to sustainable development goals. Sci. Total Environ. 738. https://doi.org/10.1016/j.scitotenv.2020.139693

Gray, S.A., Gray, S., Cox, L.J., Henly-Shepard, S., 2013. Mental Modeler: A fuzzy-logic cognitive mapping modeling tool for adaptive environmental management, in: Proceedings of the Annual Hawaii International Conference on System Sciences. https://doi.org/10.1109/HICSS.2013.399

Gray, S.A., Gray, S., de Kok, J.L., Helfgott, A.E.R., O'Dwyer, B., Jordan, R., Nyaki, A., 2015. Using fuzzy cognitive mapping as a participatory approach to analyze change, preferred states, and perceived resilience of social-ecological systems. Ecol. Soc. 20. https://doi.org/10.5751/ES-07396-200211

Gray, S.A., Zanre, E., Gray, S.R.J., 2014. Fuzzy cognitive maps as representations of mental models and group beliefs. Intell. Syst. Ref. Libr. 54. https://doi.org/10.1007/978-3-642-39739-4_2

Hafezi, M., Giffin, A.L., Alipour, M., Sahin, O., Stewart, R.A., 2020. Mapping long-term coral reef ecosystems regime shifts: A small island developing state case study. Sci. Total Environ. 716. https://doi.org/10.1016/j.scitotenv.2020.137024

Harich, J., 2010. Change resistance as the crux of the environmental sustainability problem. Syst. Dyn. Rev. 26. https://doi.org/10.1002/sdr.431

HCFCD, 2020. Wet bottom detention basins with water quality features.

House-Peters, L.A., Chang, H., 2011. Urban water demand modeling: Review of concepts, methods, and organizing principles. Water Resour. Res. 47. https://doi.org/10.1029/2010WR009624

Hovmand, P., Rouwette, E., Andersen, D.F., Richardson, G.P., Calhoun, A., Rux, K., Hower, T., 2011. Scriptapedia: a handbook of scripts for developing structured group model building sessions, in: Proceedings of the 2011 International System Dynamics Conference.

Inam, A., Adamowski, J., Halbe, J., Prasher, S., 2015. Using causal loop diagrams for the initialization of stakeholder engagement in soil salinity management in agricultural watersheds in developing countries: A case study in the Rechna Doab watershed, Pakistan. J. Environ. Manage. 152. https://doi.org/10.1016/j.jenvman.2015.01.052

Kabisch, N., Frantzeskaki, N., Pauleit, S., Naumann, S., Davis, M., Artmann, M., Haase, D., Knapp, S., Korn, H., Stadler, J., Zaunberger, K., Bonn, A., 2016. Nature-based solutions to climate change mitigation and adaptation in urban areas: Perspectives on indicators, knowledge gaps, barriers, and opportunities for action. Ecol. Soc. 21. https://doi.org/10.5751/ES08373-210239

Kaljonen, M., Varjopuro, R., Giełczewski, M., lital, A., 2012. Seeking policy-relevant knowledge: A comparative study of the contextualisation of participatory scenarios for the Narew River and Lake Peipsi. Environ. Sci. Policy 15. https://doi.org/10.1016/j.envsci.2011.10.006

Keshta, N., Elshorbagy, A., Carey, S., 2009. A generic system dynamics model for simulating and evaluating the hydrological performance of reconstructed watersheds. Hydrol. Earth Syst. Sci. 13. https://doi.org/10.5194/hess-13-865-2009

Kim, M., You, S., Chon, J., Lee, J., 2017. Sustainable land-use planning to improve the coastal resilience of the social-ecological landscape. Sustain. 9. https://doi.org/10.3390/su9071086

Kokkinos, K., Karayannis, V., Moustakas, K., 2020. Circular bio-economy via energy transition supported by Fuzzy Cognitive Map modeling towards sustainable low-carbon environment. Sci. Total Environ. 721. https://doi.org/10.1016/j.scitotenv.2020.137754

Kosko, B., 1986. Fuzzy cognitive maps. Int. J. Man. Mach. Stud. 24. https://doi.org/10.1016/S0020-7373(86)80040-2

Kotir, J.H., 2020. Managing and Sustaining the Coupled Water-Land-Food Systems in the Context of Global Change: How Qualitative System Dynamic Modelling Can Assist in Understanding and Designing High-Leverage Interventions, in: Natural Resources Management and Biological Sciences.

Kotir, J.H., Smith, C., Brown, G., Marshall, N., Johnstone, R., 2016. A system dynamics simulation model for sustainable water resources management and agricultural development in the Volta River Basin, Ghana. Sci. Total Environ. 573. https://doi.org/10.1016/j.scitotenv.2016.08.081

Kronenberg, J., 2015. Why not to green a city? Institutional barriers to preserving urban ecosystem services. Ecosyst. Serv. 12. https://doi.org/10.1016/j.ecoser.2014.07.002

Levy, Z.F., Smardon, R.C., Bays, J.S., Meyer, D., 2014. A point source of a different color: Identifying a gap in united states regulatory policy for "green" CSO treatment using constructed wetlands. Sustain. 6. https://doi.org/10.3390/su6052392

Li, H., Ding, L., Ren, M., Li, C., Wang, H., 2017. Sponge city construction in China: A survey of the challenges and opportunities. 
Non-peer reviewed EarthArXiv preprint.

Under review by Environmental Science, Policy, \& Management.

Water (Switzerland) 9. https://doi.org/10.3390/w9090594

Li, L., Simonovic, S.P., 2002. System dynamics model for predicting floods from snowmelt in north American prairie watersheds. Hydrol. Process. 16. https://doi.org/10.1002/hyp.1064

Li, Z., Dong, M., Wong, T., Wang, J., Kumar, A.J., Singh, R.P., 2018. Objectives and indexes for implementation of sponge cities-A case study of Changzhou City, China. Water (Switzerland) 10. https://doi.org/10.3390/w10050623

Mashaly, A.F., Fernald, A.G., 2020. Identifying capabilities and potentials of system dynamics in hydrology and water resources as a promising modeling approach for water management. Water (Switzerland). https://doi.org/10.3390/w12051432

McRae, A.M., 2016. Case study: A conservative approach to green roof benefit quantification and valuation for public buildings. Eng. Econ. 61. https://doi.org/10.1080/0013791X.2016.1186255

Mirchi, A., Madani, K., Watkins, D., Ahmad, S., 2012. Synthesis of System Dynamics Tools for Holistic Conceptualization of Water Resources Problems. Water Resour. Manag. 26. https://doi.org/10.1007/s11269-012-0024-2

Moon, Y.B., 2017. Simulation modelling for sustainability: a review of the literature. Int. J. Sustain. Eng. https://doi.org/10.1080/19397038.2016.1220990

Muscat, A., de Olde, E.M., Kovacic, Z., de Boer, I.J.M., Ripoll-Bosch, R., 2021. Food, energy or biomaterials? Policy coherence across agro-food and bioeconomy policy domains in the EU. Environ. Sci. Policy 123. https://doi.org/10.1016/j.envsci.2021.05.001

Nesshöver, C., Assmuth, T., Irvine, K.N., Rusch, G.M., Waylen, K.A., Delbaere, B., Haase, D., Jones-Walters, L., Keune, H., Kovacs, E., Krauze, K., Külvik, M., Rey, F., van Dijk, J., Vistad, O.I., Wilkinson, M.E., Wittmer, H., 2017. The science, policy and practice of nature-based solutions: An interdisciplinary perspective. Sci. Total Environ. https://doi.org/10.1016/j.scitotenv.2016.11.106

Nilsson, M., Zamparutti, T., Petersen, J.E., Nykvist, B., Rudberg, P., Mcguinn, J., 2012. Understanding Policy Coherence: Analytical Framework and Examples of Sector-Environment Policy Interactions in the EU. Environ. Policy Gov. 22. https://doi.org/10.1002/eet.1589

O'Donnell, E.C., Lamond, J.E., Thorne, C.R., 2017. Recognising barriers to implementation of Blue-Green Infrastructure: a Newcastle case study. Urban Water J. 14. https://doi.org/10.1080/1573062X.2017.1279190

Olazabal, M., Chiabai, A., Foudi, S., Neumann, M.B., 2018. Emergence of new knowledge for climate change adaptation. Environ. Sci. Policy 83. https://doi.org/10.1016/j.envsci.2018.01.017

Osoba, O., Kosko, B., 2019. Causal modeling with feedback fuzzy cognitive maps, in: Social-Behavioral Modeling for Complex Systems. https://doi.org/10.1002/9781119485001.ch25

Özesmi, U., Özesmi, S.L., 2004. Ecological models based on people's knowledge: A multi-step fuzzy cognitive mapping approach. Ecol. Modell. 176. https://doi.org/10.1016/j.ecolmodel.2003.10.027

Pagano, A., Pluchinotta, I., Pengal, P., Cokan, B., Giordano, R., 2019. Engaging stakeholders in the assessment of NBS effectiveness in flood risk reduction: A participatory System Dynamics Model for benefits and co-benefits evaluation. Sci. Total Environ. 690. https://doi.org/10.1016/j.scitotenv.2019.07.059

Pande, S., Sivapalan, M., 2017. Progress in socio-hydrology: a meta-analysis of challenges and opportunities. Wiley Interdiscip. Rev. Water 4. https://doi.org/10.1002/wat2.1193

Paterson, K.C., Holden, N.M., 2019. Assessment of policy conflict using systems thinking: A case study of carbon footprint reduction on Irish dairy farms. Environ. Sci. Policy 101. https://doi.org/10.1016/j.envsci.2019.07.008

Perrone, A., Inam, A., Albano, R., Adamowski, J., Sole, A., 2020. A participatory system dynamics modeling approach to facilitate collaborative flood risk management: A case study in the Bradano River (Italy). J. Hydrol. 580. https://doi.org/10.1016/j.jhydrol.2019.124354

Pluchinotta, I., Pagano, A., Giordano, R., Tsoukiàs, A., 2018. A system dynamics model for supporting decision-makers in irrigation water management. J. Environ. Manage. 223. https://doi.org/10.1016/j.jenvman.2018.06.083

Ramírez-Agudelo, N.A., Anento, R.P., Villares, M., Roca, E., 2020. Nature-based solutions for water management in peri-urban areas: Barriers and lessons learned from implementation experiences. Sustain. https://doi.org/10.3390/su12239799

Raskin, J.D., 2002. Constructivism in psychology: Personal construct psychology, radical constructivism, and social constructionism. Am. Commun. J.

Raymond, C.M., Frantzeskaki, N., Kabisch, N., Berry, P., Breil, M., Nita, M.R., Geneletti, D., Calfapietra, C., 2017. A framework for assessing and implementing the co-benefits of nature-based solutions in urban areas. Environ. Sci. Policy 77. https://doi.org/10.1016/j.envsci.2017.07.008

Reyes-Mendy, F., Arriagada, R.A., Reyes-Paecke, S., Bello, A., Tobar, A., 2014. Policy statement coherence: A methodological proposal to assess environmental public policies applied to water in Chile. Environ. Sci. Policy 42. https://doi.org/10.1016/j.envsci.2014.06.001

RGME, 2021. Residential Green Infrastructure (Gl) Standards for Imagination Zones.

Richardson, G.P., 2011. Reflections on the foundations of system dynamics. Syst. Dyn. Rev. 27. https://doi.org/10.1002/sdr.462

Richmond, B., 1993. Systems thinking: Critical thinking skills for the 1990 s and beyond. Syst. Dyn. Rev. 9. https://doi.org/10.1002/sdr.4260090203

Roxas, F.M.Y., Rivera, J.P.R., Gutierrez, E.L.M., 2019. Locating Potential Leverage Points In A Systems Thinking Causal Loop Diagram Toward Policy Intervention. World Futures 75. https://doi.org/10.1080/02604027.2019.1654784

Ruangpan, L., Vojinovic, Z., Di Sabatino, S., Leo, L.S., Capobianco, V., Oen, A.M.P., Mcclain, M.E., Lopez-Gunn, E., 2020. Naturebased solutions for hydro-meteorological risk reduction: a state-of-the-art review of the research area. Nat. Hazards Earth Syst. 
Non-peer reviewed EarthArXiv preprint.

Under review by Environmental Science, Policy, \& Management.

Sci. 20. https://doi.org/10.5194/nhess-20-243-2020

Ruiz, I., Sanz-Sánchez, M.J., 2020. Effects of historical land-use change in the Mediterranean environment. Sci. Total Environ. 732. https://doi.org/10.1016/j.scitotenv.2020.139315

Ryan, E., Pepper, M., Munoz, A., 2021. Causal Loop Diagram Aggregation Towards Model Completeness. Syst. Pract. Action Res. 34. https://doi.org/10.1007/s11213-019-09507-7

Santoro, S., Pluchinotta, I., Pagano, A., Pengal, P., Cokan, B., Giordano, R., 2019. Assessing stakeholders' risk perception to promote Nature Based Solutions as flood protection strategies: The case of the Glinščica river (Slovenia). Sci. Total Environ. 655. https://doi.org/10.1016/j.scitotenv.2018.11.116

Sarabi, S., Han, Q., Romme, A.G.L., de Vries, B., Valkenburg, R., den Ouden, E., 2020. Uptake and implementation of Nature-Based Solutions: An analysis of barriers using Interpretive Structural Modeling. J. Environ. Manage. 270. https://doi.org/10.1016/j.jenvman.2020.110749

Shahvi, S., Mellander, P.E., Jordan, P., Fenton, O., 2021. A Fuzzy Cognitive Map method for integrated and participatory water governance and indicators affecting drinking water supplies. Sci. Total Environ. 750. https://doi.org/10.1016/j.scitotenv.2020.142193

Singh, P.K., Chudasama, H., 2020. Evaluating poverty alleviation strategies in a developing country. PLoS One 15. https://doi.org/10.1371/journal.pone.0227176

Solheim, A., Capobianco, V., Oen, A., Kalsnes, B., Wullf-Knutsen, T., Olsen, M., Seppia, N. Del, Arauzo, I., Balaguer, E.G., Strout, J.M., 2021. Implementing nature-based solutions in rural landscapes: Barriers experienced in the phusicos project. Sustain. 13. https://doi.org/10.3390/su13031461

Stepp, M.D., Winebrake, J.J., Hawker, J.S., Skerlos, S.J., 2009. Greenhouse gas mitigation policies and the transportation sector: The role of feedback effects on policy effectiveness. Energy Policy 37. https://doi.org/10.1016/j.enpol.2009.03.013

Sternam, J.D., 2002. System Dynamics: Systems Thinking and Modeling for a Complex World. MIT Sloan Sch. Manag. 147.

Storey, A., Blount, J., Talbott, M., 2011. Harris County low impact development \& green infrastructure design criteria for storm water management.

Sušnik, J., Vamvakeridou-Lyroudia, L.S., Savić, D.A., Kapelan, Z., 2012. Integrated System Dynamics Modelling for water scarcity assessment: Case study of the Kairouan region. Sci. Total Environ. 440. https://doi.org/10.1016/j.scitotenv.2012.05.085

Tayouga, S.J., Gagné, S.A., 2016. The socio-ecological factors that influence the adoption of green infrastructure. Sustain. https://doi.org/10.3390/su8121277

Thorne, C.R., Lawson, E.C., Ozawa, C., Hamlin, S.L., Smith, L.A., 2018. Overcoming uncertainty and barriers to adoption of BlueGreen Infrastructure for urban flood risk management. J. Flood Risk Manag. 11. https://doi.org/10.1111/jfr3.12218

Turner, B.L., Menendez, H.M., Gates, R., Tedeschi, L.O., Atzori, A.S., 2016. System dynamics modeling for agricultural and natural resource management issues: Review of some past cases and forecasting future roles. Resources. https://doi.org/10.3390/resources5040040

UN Environment Programme, 2019. Nature-based solutions for climate manifesto. Https://Www. Unenvironment.Org/Nature-BasedSolutions-Climate.

UNEP, 2019. The UN Environment Programme and nature-based solutions.

Vásquez, A., Devoto, C., Giannotti, E., Velásquez, P., 2016. Green Infrastructure Systems Facing Fragmented Cities in Latin America - Case of Santiago, Chile, in: Procedia Engineering. https://doi.org/10.1016/j.proeng.2016.08.602

Vogel, J.R., Moore, T.L., Coffman, R.R., Rodie, S.N., Hutchinson, S.L., McDonough, K.R., McLemore, A.J., McMaine, J.T., 2015. Critical Review of Technical Questions Facing Low Impact Development and Green Infrastructure: A Perspective from the Great Plains. Water Environ. Res. 87. https://doi.org/10.2175/106143015x14362865226392

Voinov, A., Jenni, K., Gray, S., Kolagani, N., Glynn, P.D., Bommel, P., Prell, C., Zellner, M., Paolisso, M., Jordan, R., Sterling, E., Schmitt Olabisi, L., Giabbanelli, P.J., Sun, Z., Le Page, C., Elsawah, S., BenDor, T.K., Hubacek, K., Laursen, B.K., Jetter, A., Basco-Carrera, L., Singer, A., Young, L., Brunacini, J., Smajgl, A., 2018. Tools and methods in participatory modeling: Selecting the right tool for the job. Environ. Model. Softw. 109. https://doi.org/10.1016/j.envsoft.2018.08.028

Wamsler, C., Wickenberg, B., Hanson, H., Alkan Olsson, J., Stålhammar, S., Björn, H., Falck, H., Gerell, D., Oskarsson, T., Simonsson, E., Torffvit, F., Zelmerlow, F., 2020. Environmental and climate policy integration: Targeted strategies for overcoming barriers to nature-based solutions and climate change adaptation. J. Clean. Prod. 247. https://doi.org/10.1016/j.jclepro.2019.119154

Zomorodian, M., Lai, S.H., Homayounfar, M., Ibrahim, S., Fatemi, S.E., El-Shafie, A., 2018. The state-of-the-art system dynamics application in integrated water resources modeling. J. Environ. Manage. https://doi.org/10.1016/j.jenvman.2018.08.097

Zuniga-Teran, A.A., Staddon, C., de Vito, L., Gerlak, A.K., Ward, S., Schoeman, Y., Hart, A., Booth, G., 2020. Challenges of mainstreaming green infrastructure in built environment professions. J. Environ. Plan. Manag. 63. https://doi.org/10.1080/09640568.2019.1605890 